Thomas Gutmann

\author{
«"KEEPIN 'EM DOWN IN THE \\ FARM AFTER THEY'VE SEEN \\ PAREE": CONTRADICCIONES \\ DE LA CONCEPCIÓN \\ COMUNITARISTA DEL DERECHO»
}




\title{
«KEEPIN 'EM DOWN IN THE FARM AFTER THEY'VE SEEN PAREE»: CONTRADICCIONES DE LA CONCEPCIÓN COMUNITARISTA DEL DERECHO*
}

\author{
Thomas Gutmann \\ Universidad de Munich
}

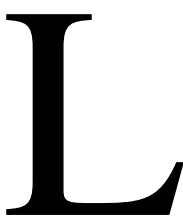

a Teoría de la justicia de John Rawls marcó, a comienzos de los años setenta, una nueva fase en el desarrollo de la filosofía política y social liberal de base deontológica. Asimismo, la discusión sobre dicha obra operó como un catalizador para el renacimiento de toda una serie de concepciones críticas al liberalismo, las cuales aparecen reunidas bajo el término del «comunitarismo», denominación en la que vienen a confluir posiciones filosóficas y sociológicas de muy diversa índole. De entre los planteamientos incluidos en esa denominación, pueden citarse, por ejemplo, la filosofía de la virtud de Alasdayr MacIntyre, originalmente aristotélica y en la actualidad decididamente tomista; la ontología de la comunidad de Michael Sandel; la antropología hermenéutica de Charles Taylor, inspirada sobre todo en Hegel, pero también en Heidegger y en el último Wittgenstein; la pretensión de Martha Nussbaum de fundar una «socialdemocracia aristotélica»; los intentos sociológicos, si bien con aspiraciones normativas, del equipo de Robert Bellah de revitalización de las bases republicanas y bíblicas de Norteamérica; la «radicalmente particularista» teoría de la justicia de Michael Walzer; el «liberalismo posmoderno burgués», de orientación pragmática, de Richard Rorty, y, por último, la democracia participativa de base popular de Benjamin Barber. Esta diversidad es indicativa, además, de que ese término «comunitarismo» es, en realidad, una atribución realizada por la literatura secundaria, ajena, por lo general, a los propios autores citados. Como autodescripción, dicho término es sólo empleado -además de por Michael Sandel ${ }^{1}$ - por el brazo político del «movimiento», reunido en torno al economista Amitai Etzioni, y apenas vinculado al núcleo de la dis-

\footnotetext{
* Publicado originalmente en Archiv für Rechts- und Sozialphilosophie, 1997, pp. 37 ss. Traducción del alemán por Rafael Alcácer Guirao (Departamento de Derecho Penal. Universidad Complutense de Madrid). Siguiendo la redacción del autor, las citas en inglés han permanecido en su idioma original.
} 
cusión filosófica ${ }^{2}$. Por otra parte, la adición que normalmente suele hacerse del prefijo «neo» al adjetivo «comunitarista» ${ }^{3}$, revela también que el fenómeno se trata sobre todo de un revival: los argumentos del círculo de los «comunitaristas» se sustentan primordialmente ${ }^{4}$ en las inagotables fuentes del neoaristotelismo ${ }^{5}$, en Hegel y su crítica a Kant centrada en la idea de la eticidad sustancial \{substantiellen Sittlichkeit\}, o en la tradición del «republicanismo cívico», cuyos antecedentes genealógicos gustan estos autores de situar desde en Aristóteles y Rousseau, hasta en Jefferson, pasando por Maquiavelo ${ }^{6}$, y entre los cuales suele figurar también el nombre de Hannah Ahrendt ${ }^{7}$. En este sentido, no puede hablarse de $l a$ escuela comunitarista, pues no todos los autores citados sostienen por igual todas y cada una de las tesis que vienen a conformar el síndrome comunitarista.

Una primera diferencia genérica puede establecerse a partir de la clasificación que Sheila Benhabib hace de las posiciones comunitaristas en «integracionistas» y «participativas» ${ }^{8}$. Los comunitaristas integracionistas parten, en general, de que la anomia propia de las modernas sociedades sólo puede enmendarse con la revitalización de valores sustanciales, a través de una verdadera comunitarización \{Vergemeinschaftung\}, y un retroceso al menos parcial en la tendencia de la diferenciación social; en consecuencia, para este sector, antes que la protección de los derechos y libertades individuales, la atención prioritaria se dirigirá a la protección de la integridad de

${ }^{1}$ Michael Sandel, Introduction, en, el mismo (editor), Liberalism and Its Critics, New York, 1984, pp. 1 ss. (5 ss.)

${ }^{2}$ Cfr. sobre todo Amitai Etzioni, The Spirit of Community. Rights, Responsibilities and the Communitarian Agenda, New York, 1993 (p. 18: «Sé un comunitarista - Enrólate al movimiento»); y, el mismo, (editor), New Communitarian Thinking, Charlottesville, 1995, así como la revista cuatrimestral The Responsive Community. Rights and Responsibilities.

${ }^{3}$ Cfr. Amy Gutmann, Communitarian Critics to Liberalism, en Philosophy and Public Affairs 14 (1985), pp. 308 ss., citado aquí según la traducción alemana: Die Kommunitaristischen Kritiker der Liberalismus, en Axel Honeth (editor), Kommunitarismus. Eine Debatte über die moralischen Grundlagen moderner Gesellschaften, Frankfurt/New York, 1993, pp. 68 ss.

${ }^{4}$ Cfr. Michael Sandel, Introduction (nota 1), p. 7. Sandel no menciona la influencia del pragmatismo norteamericano, por ejemplo, en relación a Richard Rorty, a Benjamin Barber o a Michael Walzer.

${ }_{5}^{5}$ Cfr. sobre ello Herbert Schnädelblacht, Was ist Neoaristotelismus?, en el mismo (editor), Zur Rehabilitierung des Animal rationale. Vorträge und Abhandlungen, 2, Frankfurt/Main, 1992, pp. 205 ss.

${ }^{6}$ Cfr. J.G.A. Pocock, The Machiavelliean Moment. Florentine Political Thought and the Atlantic Republican Tradition, Priceton, 1975.

${ }^{7}$ Cfr. en especial Hannah Ahrendt, Über die Revolution, München/Zurich, 1974.

8 Vid. Sheila Benhabib, Autonomy, Modernity, and Community. Communitarianism and Critical Social Theory in Dialogue; en Axel Honeth (editor), Zwischenbetrachtungen im Prozeb der Aufklärung. Jürgen Habermas zum 60. Geburstag, Frankfurt/Main, 1989, pp. 373 ss. (pp. 385 ss.). 
los vínculos comunitarios. Es a esta concepción a la que se dirigirá el grueso de las siguientes consideraciones.

La línea trazada por Benhabib secciona, además, la misma tradición del civic republicanism. La rama participativa, dentro de la que puede destacarse a Benjamin Barber, no ahorra, ciertamente, críticas sobre la naturaleza privatista de la «democracia liberal», pero no comparte los afectos antimodernos y «nostalgias republicanas» (Barber) de Hannah Ahrendt o Leo Strauss 9 . Por el contrario, asume como un hecho la diferenciación y el pluralismo social presentes en las modernas sociedades, con los conflictos a ello inmanentes, y concibe la sociedad, en lugar de como un preexistente horizonte valorativo o una identidad histórica, como el ámbito público donde tiene lugar la común participación política de ciudadanos activos ${ }^{10}$. Esta teoría de la democracia radical, en la estela de un Rousseau reconciliado con la modernidad ${ }^{11}$, tiene puntos de contacto con el «nuevo revival republicano» en la teoría constitucionalista americana ${ }^{12}$, con la lectura democrática radical de la filosofía del Derecho de Kant realizada por Ingeborg Mauss ${ }^{13}$, así como, en aspectos puntuales, con el concepto de la democracia deliberativa de Jürgen Habermas ${ }^{14}$. En cualquier caso, las objeciones que contra esta concepción se han interpuesto por parte de las teorías «realistas» de la democracia, no pertenecen ya a la discusión sobre el comuni-

${ }^{9}$ Cfr. sobre ello la dura crítica de Benjamin Barber a Alasdair MacIntyre, en Barber, The Conquest of Politics. Liberal Philosophy in Democratic Times, Princeton 1988, pp. 177 ss.

${ }^{10}$ Cfr. Benjamin Barber, Strong Democracy. Participatory Politics for a New Age, Berkeley, 1984; citado según su traducción al alemán : Starke Demokratie, Hamburg, 1994, pp. 31 ss., 100, 104, 122 ss., 142 ss., 152 ss., 219.

11 Vid. también Benjamin Barber, The Conquest of Politics (nota 9), pp. 12 ss.

${ }_{12}$ Vid., por ejemplo, Frank Michelmann, Law's Republic, en The Yale Law Journal 97 (1988), pp. 1493 ss., 1495 («I will contend \{...\} that republican constitutional thought is not indissolubly tied to any static, parochial or coercive communitarianism»); Cass R. Sunstein, Beyond the Republican Revival, en The Yale Law Journal 97 (1988), pp. 1539 ss. Cfr., en relación a este tema, la exposición crítica de Jürgen Habermas, Faktizität und Geltung. Beiträge zur Diskurstheorie des Rechts und des demokratischen Rechtstaats, Frankfurt/Main, 1992, pp. 324 ss. Cfr. también Stephen A. Gardbaum, Law, Politics, and the Claims of Community, en Michigan Law Review 90 (1992), pp. 685 ss. (749 ss.), y Paul W. Kahn, Community in Contemporary Constitutional Theory, en The Yale Law Journal 99 (1989), pp. 1 ss.

${ }_{13}$ Ingeborg Maus, Zur Aufklärung der Demokratietheorie. Rechts- und demokratietheoretische Überlegungen im Anschlub an Kant, Frankfurt/Main, 1992, pp. 148 ss., 274 ss., 298 ss. Según Maus, Kant vincula la vigencia y validez del Derecho únicamente a la base procedimental y democrática de su génesis. El Kant «rousseauficado» de Maus parece por tanto fundar los derechos de participación sobre todo en la actividad de legislador. Maus coincide aquí con Michael Walzer y con Benjamin Barber en la confrontación crítica entre la filosofía de expertos y la democracia participativa, y especialmente en la crítica de que la teoría de Rawls conlleva el peligro «de independizar la justicia de los esquemas óptimos de distribución de los procedimientos democráticos de establecimiento de los criterios de distribución» (p. 43). Cfr. sobre esto la similar argumentación de Barber en The Conquest of Politics (nota 9), pp. 54 ss.

${ }^{14}$ Cfr. Jürgen Habermas, Faktizität und Geltung (nota 12), especialmente pp. 349 ss. 
tarismo. Lo que el presente trabajo pretende es poner de manifiesto que los argumentos fundamentales del comunitarismo «integracionista», debido a sus limitaciones teóricas, no pueden erigirse en alternativa a la fundamentación posconvencional de la ética y al Estado de Derecho liberal. Sin pretensión de fundamentar esta última opción citada, se intentará demostrar que el conjunto de las argumentaciones teóricas del comunitarismo incurre en contradicciones básicas y que, ya en el nivel de teoría del actor moral (1), ya en el de la metaética (2), ya, por último, en el de la teoría de la sociedad (3), está sostenido en presupuestos tanto descriptivamente inadecuados como normativamente poco convincentes.

\section{La tesis de la constitución}

La argumentación del comunitarismo se inicia con una crítica a las bases antropológicas «atomísticas» de la reciente filosofía social «liberal». Según esta primera tesis comunitarista, los hombres permanecen siempre ontogenéticamente inmersos en sus comunidades, las cuales, por tanto, poseen un carácter esencial, y no meramente accidental, para la construcción de la identidad de los mismos.

(1) El locus classicus de esta nueva discusión, históricamente reconducible a la idea aristotélica del hombre como zoon politikon ${ }^{15}$, es la crítica de Michael Sandel a la Teoría de la Justicia de John Rawls ${ }^{16}$. A la concepción de Rawls (la cual a estas alturas no necesita ser presentada) objeta Sandel que su derivación contractual de los principios básicos de la justicia institucional está basada en una antropología filosófica que concibe al sujeto como un «yo radicalmente desvinculado» que elige libremente y sin impedimentos sus intereses, sus necesidades, sus vínculos e incluso su propia identidad, y que, en este sentido, es «anterior» a sus fines y objetivos ${ }^{17}$. Pero la teoría de Rawls es empleada por Sandel sólo como pars pro toto; su crítica, en última instancia, sostiene que toda concepción deontológica de la ética desde Kant, y más allá de ello, toda teoría filosófico-jurídica o ética que parta de la primacía de los derechos individuales y de principios básicos y universalizables de justicia frente a las representaciones sobre lo bueno de la comunidad, está metodológicamente obligada a asumir dicho yo «aislado» y voluntarista ${ }^{18}$. La tesis principal de Sandel radica en que, en consecuen-

${ }^{15}$ Cfr. Aristóteles, Politik, 1253a.

${ }_{16}$ Michael Sandel, Liberalism and the Limits of Justice, Cambridge 1982; el mismo, Die verfahrensrechtliche Republik und das ungebundene Selbst, 1984, en, Axel Honneth (editor), Kommunitarismus (nota 3), pp. 18 ss.

${ }^{17}$ Cfr. Sandel, Liberalism (nota 16), pp. 15 ss, 54 ss.

${ }_{18}$ Cfr. Sandel, Liberalism (nota 16), pp. 1 ss., 156 ss. Sandel, acertadamente, agrupa esta familia teórica basada en la argumentación universalista y procedimentalista bajo la denominación de «liberalismo deontológico» 
cia, todas estas concepciones deben ser rechazadas, puesto que los hombres, ya desde una perspectiva fenomenológica, no pueden ser concebidos y percibidos como esos entes noumenales que la tradición deontológica ${ }^{19}$ desde Kant hasta Rawls (y Habermas) pretende que sean ${ }^{20}$. A la hora de reconocernos a nosotros mismos como actores morales debemos, por el contrario, preguntarnos siempre por nuestra identidad, y ello no puede hacerse sino a través de descubrir introspectivamente la comunidad en que vivimos, que con su concepción particular de lo bueno es constituiva de dicha identidad: «And in so far as our constitutive self-understandings comprehend a wider subject than the individual alone, whether a family or tribe or city or class or nation or people, to this extent they define a community in the constitutive sense» ${ }^{21}$.

(2) De forma similar a Sandel, aunque bajo explícitas premisas aristotélicas, parte Alasdair MacIntyre del «hecho» de que «el yo debe encontrar su identidad moral en y a través de su pertenencia a comunidades como la familia, la vecindad, el Estado o la casta» ${ }^{22}$.

(3) Por último, Charles Taylor, guiado por su reconstrucción de la idea hegeliana de la eticidad $\{\text { Sittlichkeit }\}^{23}$, e inspirado además por el Ser $y$ tiempo de Heidegger y por la filosofía de los juegos del lenguaje del Wittgenstein de las Investigaciones filosóficas, desarrolla una variante filosófico-lingüística de la tesis de la constitución. Para Taylor, el mundo del actor social viene determinado por su forma de vida y por su historia. Esos contextos o «marcos» han formado una base cognitiva y normativa para la autocomprensión de los sujetos, los cuales tuvieron que permanecer parcialmente opacos para éstos. La consecuente constatación de que el actuar sólo puede ser un «actuar intervenido» \{beteiligtes Handel\}, desmiente por tanto la representación dominante en el «racionalismo moderno», asumida como un hecho de sentido común por nuestra civilización, de que el yo puede adoptar una «mirada desde ninguna parte» (Thomas Nagel ${ }^{24}$ ) que tras-

${ }^{19}$ La crítica comunitarista da por supuesta la solidez de la crítica deontológica al utilitarismo; en cualquier caso, no parece tomar en serio las posiciones consecuencialistas. Cfr. Sandel, Liberalism (nota 16) pp. 2 ss. ; Charles Taylor, The Diversity of Goods, en, el mismo, Philosophical Papers, volumen 2, Cambridge 1985, pp. 230 ss., así como Alasdair MacIntyre, After Virtue. A Study in Moral Theory, Notre Dame 1981, citado aquí por la traducción alemana: Der Verlust der Tugend. Zur moralischen Krise der Gegenwart, Frankfurt a. Main / New York, 1987, pp. 89 ss.

${ }^{20}$ Vid. Sandel, Liberalism, (nota 16), p. 14.

${ }^{21}$ Sandel, Liberalism, (nota 16), p. 172

22 Alasdair MacIntyre, Der Verlust der Tugend (nota 19), p. 295.

${ }^{23}$ Charles Taylor, Hegel, 1975, Frankfurt a. Main, 1993 (2 edición), pp. 492 ss., 506 ss., 537 ss.

${ }^{24}$ Thomas Nagel, The View from Nowhere, Oxford 1986. 
cienda ese trasfondo ${ }^{25}$. En particular, la idea del yo como un actor responsable lleva, según Taylor, implícita la imagen de un sujeto que, más allá de meras preferencias, es capaz de establecer valoraciones a partir de «valores fuertes», es decir, capaz de una auténtica autointerpretación de su propia vida como un todo ${ }^{26}$. Pero esos valores fuertes no pueden ser fruto de una elección radical, sino que, por un lado, deben formar parte del sentido uniforme de la propia biografía como una «narración» con sentido; por otro, sólo pueden existir en el ámbito de su articulación lingüística. El lenguaje, a su vez, sólo existe y perdura en el seno de comunidades de lenguaje como formas concretas de vida, en las que al mismo tiempo se ha conformado un horizonte valorativo. Taylor, a partir del postulado de Wittgenstein relativo a la imposibilidad de los lenguajes privados, llega, así, a la conclusión «trascendental», de que la experiencia de la propia identidad moral ha de venir siempre ontogenéticamente constituida por la existencia de previas y concretas comunidades ${ }^{27}$.

\section{Límites del poder normativo de lo fáctico}

La tesis de la constitución, como crítica fundamental a los sostenes normativos del Estado de Derecho liberal, no viene a ofrecer en realidad lo que prometía:

(1) En primer lugar, se agota en una discusión irrelevante. Un atomismo extremo, que sostiene que la teoría jurídica y social debe asumir al hombre en su existencia presocial y que el significado de la socialización surge de la nada, puede encontrarse en la antropología social micológica de Thomas Hobbes ${ }^{28}$, en algunas partes de la teoría de la decisión racional y en algunas concepciones libertarias extremas en la estela de Locke, entre quienes, como claro exponente, figura el primer Robert Nozick ${ }^{29}$. Pero la ase-

${ }^{25}$ Cfr. Charles Taylor, Lichtung oder Lebensform. Parallelen zwischen Wittgenstein und Heidegger, en Brian McGuiness et. alt., Der Löwe spricht... und wir können ihn nicht verstehen. Ein Symposion an der Universität Frankfurt anläßlich des hundertsten Geburtstags von Ludwig Wittgenstein, Frankfurt a. Main 1991, pp. 94 ss. Cfr. también, el mismo, Sources of the Self. The Making of the Modern Identity, Cambridge 1989, pp. 34 ss.

${ }^{26}$ Charles Taylor, What is Human Agency?, en el mismo, Philosophical Papers, volumen 1, Cambridge 1985, pp. 15 ss. En su traducción al alemán: Was ist menschliches Handeln?, en el mismo, Negative Freiheit. Zur Kritik des neuzeitlichen Individualismus, Frankfurt a. Main 1992, pp. 9 ss.; del mismo autor, vid. Self-Interpreting Animals, en el mismo, Philosophical Papers, volumen 1, Cambridge 1985, pp. 45 ss.; así como, por último, Sandel, Liberalism (nota 16), p. 160.

${ }^{27}$ Cfr. Taylor, Sources of the Self (nota 25), pp. 26 s., 35 ss., 40, 47s.; del mismo autor, ya en, Hegel and Modern Society, Cambridge 1979, pp. 157 ss.

${ }_{28}$ Thomas Hobbes, De Cive, 8.1, en Vom Menschen - Vom Bürger, Hamburg 1977, p. 161: «hemos de admitir que los hombres - de igual forma que las setas- habrían surgido y crecido en la tierra sin previas obligaciones entre ellos».

${ }^{29}$ Robert Nozick, Anarchy, State, and Utopia, New York 1974. 
veración de que las teorías liberales o deontológicas vienen obligadas a asumir como punto de partida metodológico una imagen del hombre como un yo presocial va desencaminada. Ni la teoría de la justicia como imparcialidad de John Rawls ${ }^{30}$ ni la teoría de la acción comunicativa de Habermas, por poner dos ejemplos, están dirigidas a la fundamentación moral del intercambio de intereses entre espíritus noumenales ${ }^{31}$, sino que parten de individuos conformados a través de sus lazos y vínculos, y motivados por concretos intereses. Prácticamente ninguna postura teórica niega la importancia de una socialización dependiente de los mundos de vida para la educación moral, ni tampoco el hecho de que previamente a las posibilidades de individualización \{Individuierung \} de los sujetos exista una conformación ontogenética a través de las instancias de socialización e internalización de las formas convencionales de la moral ${ }^{32}$. Pero de los postulados deontológicos poskantianos, relativos al convencimiento de que el individuo, a partir de un determinado grado de su desarrollo moral, adquiere la capacidad de reflexionar y de poner en cuestión las convicciones morales vigentes en su ámbito de existencia, y de aprender «a distinguir entre normas vigentes y normas válidas, entre normas fácticamente reconocidas y normas dignas de reconocimiento» ${ }^{33}$, extraen Sandel y MacIntyre el erróneo presupuesto de que ese proceso sólo es posible para individuos que ya estuvieran «previamente individulizados $\{$ individuiert $\} »{ }^{34}$, es decir, que nunca hubieran experimentado la socialización ni hubieran desarrollado vínculos sociales no contingentes ${ }^{35}$.

(2) En segundo lugar, dado que el reproche sobre el atomismo carece de fundamento, la tesis de la constitución se enfrenta al dilema de que, o bien no es apta para cumplir su función de crítica al liberalismo o bien no puede ser ya considerada plausible. Si admite espacio para una autonomía moral individual, deja intactas las bases tanto de las teorías deontológicas como de las liberales, las cuales afirman la preeminencia prima facie de los

${ }_{30}$ Taylor, no obstante, excluye explícitamente a Rawls del reproche del atomismo. Cfr. Legitimation Crisis?, en Philosophical Papers, volumen 2, Cambridge 1985, pp. 248 ss. (p. 274, nota 9); en alemán: Negative Freiheit? (nota 26), pp. 235 ss. (273).

${ }^{31}$ En este sentido, Alasdair MacIntyre, How Moral Agents Became Ghosts or Why the History of Ethics Diverged from that of the Philosophy of Mind, en Synthese 53 (1982), p. 295 ss.

${ }^{32}$ Cfr. Jürgen Habermas, Individuierung durch Vergesellschaftung. George Herbert Meads Theorie der Subjektivität, en, el mismo, Nachmetaphysisches Denken, Frankfurt a. Main 1992, pp. 187 ss.

33 Jürgen Habermas, Moralbewußtsein und kommunikatives Handeln, Frankfurt a. Main 1983, pp. 137 ss.

${ }^{34}$ Sandel, Liberalism (nota16), pp. 149, 160.

${ }^{35}$ Cfr. también la mención de Rawls, en Political Liberalism, New York 1993, p. 26 ss.; y Will Kymlicka, Liberalism, Community, and Culture, Oxford 1989, pp.47 ss. 
derechos individuales. Como propuesta alternativa sólo puede entonces servir si se parte del bien común de la socialización y se postula la drástica tesis de que el contexto sociocultural, ya que conforma totalmente a los individuos, no es superable para los mismos como horizonte normativo, permaneciendo retenidos en ese ethos previamente dado. A diferencia de Taylor $^{36}$, tanto Sandel como MacIntyre parecen considerar deseable, en algunas de sus afirmaciones, la imposibilidad de una distancia reflexiva de los individuos ${ }^{37}$. Por lo demás, ello no sería, en cualquier caso, plausible, ya que lo cierto es que nosotros, al menos parcialmente, podemos claramente distanciarnos en base a razones del horizonte moral al que en nuestro medio social habitual nos hemos acostumbrado. Esto sencillamente conforma uno de los aspectos esenciales de nuestra autocomprensión y nuestra imagen de la subjetividad moral ${ }^{38}$ : Todo puede ser cuestionado, si bien no todo al mismo tiempo. Para poder continuar admitiendo la tesis de la constitución, tanto Sandel como MacIntyre se ven obligados a admitir que los individuos pueden lograr un cierto grado de distanciamiento respecto del horizonte valorativo de sus formas de vida ${ }^{39}$. Pero ese distanciamiento permanece inmanente al ethos; en el caso de MacIntyre viene limitado a una mejor comprensión de las virtudes y roles ya prefijados; y en Sandel aparece siempre menospreciado por la recurrente advertencia de que ese distanciamiento pone en peligro al agente en su identidad ${ }^{40}$ y que fuera de esa identidad previamente constituida por la comunidad, los individuos sólo estarán capacitados para perseguir representaciones deficientes, en tanto que arbitrarias, de la vida «correcta» ${ }^{41}$. Tanto para MacIntyre como para Sandel, ese pequeño ámbito de revisión de su identidad que se deja al sujeto debe ir diri-

${ }^{36}$ Cfr. Taylor, Was ist menschliches Handeln? (nota 26), pp. 41ss.; El mismo, Sources of the Self (nota 25), p. 37 ss.

37 Vid., por ejemplo, Sandel, Liberalism (nota 16) pp. 143, 149 ss. Cfr. también Alasdair MacIntyre, Intelligibility, Goods and Rules, en Journal of Philosophy 79 (1982), pp. 664 ss.

${ }^{38}$ Sobre esto vid. también la crítica de Will Kymlicka, Liberalism and Communitarianism, en Canadian Journal of Philosophy 19 (1988), 181ss.(192 ss.); el mismo, Contemporary Political Philosophy, Oxford 1990, pp. 207 ss.

${ }^{39}$ Cfr. MacIntyre, Der Verlust der Tugend (nota 19), p. 295: «Debe tenerse en cuenta (...) que, del hecho de que el yo deba hallar su identidad moral en y a partir de su pertenencia a la comunidad (...), no debe concluirse que el yo deba reconocer las restricciones morales de cada comunidad (...) en el avance motivado por esas particularidades donde yace la búsqueda del bien, de lo universal. La idea de una huida de lo particular a un ámbito de principios completamente genéricos que pertenezcan, en cuanto tal, al hombre, es una ilusión» En similar sentido, Sandel, Liberalism (nota 16), pp. 57, 179 ss.: «As a self-interpreting being, I am able to reflect on my history and in this sense to distance myself from it, but the distance is always precarious and provisional, the point of reflection never finally secured outside history itself».

${ }^{40}$ Sandel, Liberalism (nota 16), p. 179.

${ }^{41}$ Sandel, Liberalism (nota 16), pp. 168, 180. 
gido sobre todo a armonizar la parte de la persona inconscientemente conformada por la comunidad con los intereses y necesidades de ésta, a través de una adaptación consciente de los mismos a esa parte preconstituida ${ }^{42}$. Con ello, la idea de «autonomía» no denota ya el desarrollo individual de la conciencia, que pueda servir como base a una teoría de la atribución moral; desde un principio de moralidad \{Moralität $\}$, la autonomía es degradada a un principio de eticidad ${ }^{43}$. La idea de la «participación de uno mismo en la construcción de su identidad» (Sandel) ${ }^{44}$ va referida sobre todo a la capacidad que les es exigida a los individuos de pulir los bordes individuales remanentes para un mejor acoplamiento con el todo.

Por otra parte, parece indudable que la tesis de la constitución se compone de un conglomerado de elementos metafísicos, ontológicos, psicológicos y normativos. Pero dado que ni Sandel ni MacIntyre se remiten a elaboradas fundamentaciones metafísicas, que expliquen por qué los individuos sólo puede ser accidentes en la sustancia de la comunidad, cabe la opción de entender la tesis de la constitución o bien como una proposición prescriptiva que defienda que los individuos deben estar integrados plenamente en la comunidad (véase infra 3); o bien como una cuestión psicosocial a decidir empíricamente. Pero el hecho es que ni Sandel ni MacItyre intentan poner en relación su propia ontología con el estado de la investigación en dicho ámbito teórico, ni persiguen fundamentar con el bagaje de la misma por qué los individuos no puede ser capaces de dejar atrás niveles convencionales de su desarrollo moral ${ }^{45}$.

(3) En tercer y último lugar, la tesis de la constitución, desde una perspectiva normativa, carece de justificación. La pretensión de, a partir del hecho de que los hombres son seres socialmente constituidos, derivar que esas comunidades poseen prioridad valorativa sobre esos individuos, es sencillamente una falacia genética. La historia del desarrollo del individuo no determina su status moral ${ }^{46}$. Charles Taylor, quien también aquí se revela co-

${ }^{42}$ Cfr. Sandel, Liberalism (nota 16), p. 180: «In consulting my preferences, I have not only to weigh their intensity, but also to assess their suitability to the person I (already) am. [...] While the notion constitutive attachments may at first seem an obstacle to agency [...] some relative fixity of character appears essential to prevent the lapse into arbitrariness which the deontological self is unable to avoid».

${ }^{43}$ Cfr. Schnädelbach, Was ist Neoaristotelismus? (nota 5), p. 223.

${ }^{44}$ Sandel, Liberalism (nota 16), p. 153. Cfr. pp. 20, 150, 179 ss.

${ }^{45}$ Cfr. Lawrence Kohlberg, Essays on Moral Development, volumen I, San Francisco 1981.

${ }^{46}$ Vid. Sobre ello Alisa L. Carse, The Liberal Individual: A Metaphysical or Moral Embarrassment?, en Noûs 28 (1994), pp. 184 ss. Una argumentación similar puede encontrarse en Wolfgang Kersting, Die Liberalismus-Kommunitarismus-Kontroverse in der amerikanischen politischen Philosophie, en Volker Gerhard et al. (editores), Politisches Denken. Jahrbuch 1991, Stuttgart 1991, pp. 82 ss. (96 s.). 
mo el más diferenciado de los pensadores del estrecho círculo del comunitarismo, ve esto con claridad y exige separar con nitidez las cuestiones fácticas de las normativas ${ }^{47}$. Por el contrario, MacIntyre se mantiene en la posición de que un aristotelismo teleológico está sencillamente por encima de la distinción ser/deber ser propia del «empobrecido vocabulario moral» de la modernidad ${ }^{48}$; mientras que Sandel, partiendo de la existencia de ciertos sedimentos comunitarios conformadores de nuestra identidad, concluye sin más la (mayor) relevancia valorativa de dichas comunidades frente a noso$\operatorname{tros}^{49}$. La tesis (confusa en lo que a su status metodológico se refiere) de la parcial capacidad constitutiva de los individuos a través de comunidades ontogenéticamente previas no es susceptible de ofrecer argumentos ni para justificar que el marco normativo y valorativo de estas comunidades haya de sustraerse al examen de los individuos realizado bajo criterios generalizables, ni para concluir que los derechos individuales no puedan establecer barreras a las formas de persecución de esos «bienes» comunitarios.

\section{«La obligación de pertenecer»}

Esta típica «falacia comunitarista», consistente en llegar a lo prescriptivo partiendo de presupuestos descriptivos supuestamente ontológicos, sólo puede evitarse cuando se fundamenta abiertamente desde criterios normativos la importancia de la integridad de los lazos comunitarios y los horizontes valorativos colectivos frente a los derechos y fines individuales. Esta es la línea seguida por Taylor en uno de los textos clave para el debate ${ }^{50}$, sirviéndose para ello, con vagas reminiscencias hegelianas, de un criterio de deducción de deberes inferido del concepto de la libertad. A las teorías «atomísticas», que parten de la primacía de los derechos individuales sin atender a sus correspondientes deberes, opone Taylor su tesis de las «condiciones sociales de la libertad» ${ }^{51}$ : la serie de facultades propiamente humanas que conlleva normalmente la adscripción de determinados derechos morales y jurídicos, no pueden ser desarrolladas en un ámbito no social. En par-

${ }^{47}$ Charles Taylor, Cross-Purposes: The Liberal-Communitarian Debate, en Nancy Rosenblum (editora), Liberalism and the Moral Life, Cambridge 1989, pp. 159 ss. En alemán: Aneinander vorbei: Die Debatte zwischen Liberalismus und Kommunitarismus, en Honneth (editor), Kommunitarismus (nota 3), pp. 103ss.

${ }^{48}$ MacIntyre, Der Verlust der Tugend (nota 19), pp. 82 ss. (85).

${ }^{49}$ Sandel, Liberalism (nota 16), pp. 146, 153: «[T]he capacity for reflection enables the self to turn its lights inward upon itself, to inquire into its constituent nature, to survey its various attachments and acknowledge their respective claims».

${ }^{50}$ Charles Taylor, Atomism (1979), en el mismo, Philosophical Papers, volumen 2, Cambridge 1985, pp. 187 ss.

${ }^{51}$ Taylor, Atomism (nota 50), p. 209. 
ticular, la existencia de individuos capaces de autodeterminación y autonomía moral depende, según afirma Taylor, de la previa existencia de una matriz social correspondiente, en la cual esas facultades hubieran encontrado reconocimiento intersubjetivo e institucional. En consecuencia, todo aquel que por un lado acoge los derechos y libertades individuales, pero por otro rechaza los deberes inherentes al portador de esos derechos, se ve sumido en una contradicción pragmática cuando pretende mantener los requisitos socioestructurales del ejercicio de esos derechos. El punto decisivo de la deducción de Taylor de esta «significant obligation to belong» $»^{52}$ es, no obstante, que la misma no puede fundamentar la prioridad normativa de determinados ethos, sino únicamente un muy inespecífico compromiso de todo ciudadano de respaldar y proteger una «developed liberal civilization» y de no asumir los derechos individuales de una forma tal que pudiera acabar «destruyendo» (!) esas sociedades ${ }^{53}$. Una civilización como la por él propuesta se identifica, según Taylor, con la imagen de un Estado de Derecho democrático, social, tolerante y pluralista ${ }^{54}$, la cual apenas podría satisfacer, no obstante, el ahnelo de una comunidad sustancial.

Con ello llegamos a la conocida cuestión, propia de la discusión sobre el comunitarismo, relativa a cuáles han de ser los requisitos culturales y morales necesarios para la estabilidad de los Estados democráticos de Derecho ${ }^{55}$. La tan citada afirmación de Böckenförde, de que «el Estado secularizado de libertades ... \{vive\} de requisitos que él mismo no puede garantizar» ${ }^{56}$ remite a la discusión relativa a hasta qué punto puede, en las democracias occidentales, limitarse el grado de estabilidad del consenso sin llegar a erosionar el modelo de la democracia constitucional. No podemos entrar a discutir si es correcta la pretensión de que el Estado social de Derecho pueda, sin renunciar a su pluralismo inherente, vincular el reconocimiento y aceptación fáctica de su principios rectores a la propia corrección valorativa de los

${ }^{52}$ Taylor, Atomism ( nota 50), p. 206.

53 Taylor, Atomism (nota 50), p. 198.

${ }_{54}$ Taylor, Atomism (nota 50), pp. 205 ss. Taylor remarca, si bien precavidamente, que un Estado de esa clase debería proceder en forma moderadamente perfecccionista en relación al aleccionamiento de sus miembros de las capacidades humanas consideradas fundamentales. Esta afirmación no es, en todo caso, decisiva para la anteriomente expuesta «tesis social» y debería ser discutida por separado. La tesis del perfeccionismo ha sido mantenida también, y muy especialmente, por Joseph Raz, concebida como versión decididamente liberal de la misma. Vid. Raz, The Morality of Freedom, Oxford 1986 y la concepción coincidente de Stephen Mulhall / Adam Swift, Liberals and Communitarians, Oxford,etc. 1992, pp. 249ss., 290, 294.

${ }_{55}$ Cfr. sobre ello también Charles Taylor, Legitimation Crisis? (nota 30).

${ }^{56}$ Ernst-Wolfgang Böckenförde, Die Entstehung des Staates als Vorgang der Säkularisation, en, el mismo, Staat, Gesellschaft, Freiheit, Frankfurt a. Main 1976, pp. 42 ss. (60). 
mismos (Rawls ${ }^{57}$, Dworkin ${ }^{58}$ ); o bien si, a partir de procesos de racionalización del mundo de la vida y en función de la corrección del procedimiento deliberativo, puede transformarse la legalidad en legitimidad (Habermas ${ }^{59}$ ). La cuestión que aquí interesa es únicamente si la propuesta alternativa que ofrece el comunitarismo a estos modos de legitimación puede considerarse plausible.

\section{La tesis metaética: Antiuniversalismo contextualista}

La segunda tesis esencial bajo la que se agrupan las concepciones comunitaristas es de naturaleza metaética. Ésta sostiene que las normas éticas universalizables, con las cuales podría ser sometido a crítica el entramado de normas y valores concretamente vigentes en el contexto de cada comunidad dada, no son susceptibles de fundamentación.

(1) En la línea de esta tesis contextualista se orienta la concepción de Richard Rorty, quien, a partir de la noción de la contingencia del lenguaje, extrae la conclusión de que ni los juicios cognitivos ni los éticos pueden eludir la contingencia de los vocabularios locales. Debido a la inaccesibilidad de todo metavocabulario, ese etnocentrismo de las «fundamentaciones» resulta inútil; de igual forma, toda pretensión de objetividad en los juicios carece de sentido ${ }^{60}$. Rorty se diferencia de los críticos comunitaristas al liberalismo, en que para él, en el hecho de la imposibilidad de fundamentación de los principios universalistas propios de las sociedades liberales no viene implícito el retorno a imágenes pre-(pos)modernas y cerradas de lo social ${ }^{61}$ ni (al menos en las «democracias ricas del norte del Atlántico») tampoco esa imposibilidad tiene por qué afectar a la estabilidad de las prácticas democráticas tradicionales y emocionalmente respaldadas ${ }^{62}$. Esas prácticas se deben a una idea de solidaridad no sustentada en razones, sino en una sensibilidad hacia el sufrimiento de las otras personas, la cual, en una «cultura estética», se transmite primordialmente por medio del arte ${ }^{63}$. Pero Rorty

${ }^{57}$ Cfr. recientemente, Rawls, Political Liberalism (nota 35), pp. 133 ss., 149, 202.

${ }^{58}$ Cfr. Ronald Dworkin, Law's Empire, London 1991, pp. 195 ss., y, del mismo autor, Liberal Community, en California Law Review 77 (1989), pp. 479 ss.; y sobre ello Emilios A. Christodoulidis, The Suspected Intimacy Between Law and Political Community, en Archiv für Rechts- und Sozialphilosophie 80 (1994), pp. 1 ss.

${ }^{59}$ Cfr. Jürgen Habermas, Faktizität und Geltung (nota 12), S. 374, 534 así como el complemento a esa misma obra, Wie ist Legitimität durch Legalität möglich?, pp. 563 ss.

${ }^{60}$ Cfr. Richard Rorty, Kontingenz, Ironie und Solidarität, Frankfurt a. Main 1992, pp. 21ss; el mismo, Solidarität oder Objektivität, Stuttgart 1988, pp. 25 s.

${ }^{61}$ Cfr. Rorty, Kontingenz, Ironie und Solidarität ( nota 60), p.145

${ }^{62}$ Vid. Richard Rorty, Der Vorrang der Demokratie vor der Philosophie, en, el mismo, Solidarität oder Objektivität (nota 60), pp. 82 ss. (85 s., 103, 108 s.).

${ }^{63}$ Richard Rorty, Kontingenz, Ironie und Solidarität (nota 60), pp. 21 ss., 84 ss.; el mismo, Postmodern Bourgeois Liberalism, en Robert Hollinger (editor), Hermeneutics and Praxis, Notre Dame 1985, pp. 214 ss. 
confluye con las intenciones comunitaristas cuando sostiene que las justificaciones «éticas» de las instituciones y prácticas de una sociedad no se basan en fundamentaciones propias de una «metanarrativa» filosófica, sino que se configuran sólo como «relatos» históricos de la tradición local respectiva, los cuales se retroalimentan y refuerzan a partir de la autocomprensión de esa tradición como una comunidad de interpretación ${ }^{64}$. Y ello, a su vez, significa que la ética (y el contenido ético del Derecho) sólo puede ser entendida como un sinónimo de las «intenciones-de-nosotros» \{WirIntentionen\}, que pueden expresarse en la expresión «nosotros no hacemos ese tipo de cosas». Los principios de unos derechos humanos universales o de una dignidad inherente al ser humano carecen, por tanto, de toda fuerza justificante ${ }^{65}$.

(2) Alasdair MacIntyre coincide con la tesis contextualista de Rorty y con la crítica de Sandel a la deontología, ya que también él sostiene que las fundamentaciones de signo universalista no son posibles (o sólo lo son en forma decisionista). La búsqueda del individuo de su propio bien no puede guiarse por normas o sobre la base de una idea de los derechos, sino únicamente por el desempeño de los roles que enmarcan al individuo en el ethos de las tradiciones locales. En este sentido, en la historia de la decadencia planteada por MacIntyre, la teoría de la ética, desde la superación moderna del paradigma moral de Aristóteles, está per se acabada. Con el recurso a la autonomía moral de los sujetos, afirma este autor en After Virtue, desaparece toda posibilidad de fundar un contenido moral. El fracaso del proyecto de la Ilustración de conseguir una fundamentación de la moral libre de presupuestos metafísicos y religiosos, ha desembocado en la cacofonía de un cúmulo de teorías incompatibles, que ha sacado a relucir el nihilismo propio de la modernidad, el cual con Nietzsche sólo había comenzado a perfilarse ${ }^{66}$. En consecuencia, en la ontología de MacIntyre no es sólo que las nociones de los derechos subjetivos y de los derechos del hombre deban situarse en un orden jeráquicamente inferior a la noción de virtud, sino que deben ser directamente desechados: «La verdad es muy simple: esos derechos no existen, y la creencia en su existencia viene a ser como la creencia en brujas y unicornios (...) Todos los intentos surgidos de ofrecer razones concluyentes para justificar el convencimiento de que esos derechos existen han fracasado» ${ }^{67}$.

${ }^{64}$ Cfr. Richard Rorty, Pragmatism, Relativism, and Irrationalism, en, el mismo, Consequences of Pragmatism, Minneapolis 1982, pp. 160 ss.(166).

${ }_{65}$ Rorty, Solidarität oder Objektivität (nota 60), pp. 28 ss.; el mismo, Postmodern Bourgeois Liberalism (nota 63) pp. 218 ss.

${ }^{66}$ MacIntyre, Der Verlust der Tugend (nota19), pp. 53 ss., 75 ss., 96, 295.

${ }^{67}$ MacIntyre, Der Verlust der Tugend (nota 19), p. 98. 
En su obra Whose Justice?, Which Rationality?, MacIntyre da un paso más en la línea de argumentación contextualista y pasa a concebir el liberalismo y el conjunto de los derechos individuales como una, si bien deficiente, tradición más de las presentes entre las tradiciones occidentales, las cuales, dada la imposibilidad de toda racionalidad independiente del contexto, coexisten de forma inconmensurable y sin posibilidad de traducción entre sí $^{68}$. Según este autor, a largo plazo se dará la posibilidad de que una de estas líneas narrativas generadora de concepciones del mundo obtuviera, frente a las demás, una situación de hegemonía cultural (y por tanto ética), en función de su grado de coherencia interna y de su capacidad de oposición a las crisis epistemológicas; y la más apta candidata para erigirse en esa hegemonía sería la tradición del aristotelismo reformulado desde el tomismo ${ }^{69}$.

(3) También Michael Walzer, cuya teoría ocupa una posición ambigua en el debate ${ }^{70}$, ha destacado que «en materia de moral...toda argumentación no puede ser sino una proclamación de una serie de significados de vigencia general, de una comprensión colectiva sobre las cosas» dentro de una concreta comunidad política, y que supuestos principios externos y universales no pueden sustituir a las «convicciones compartidas» de una determinada forma de vida ${ }^{71}$. Los márgenes de la razón práctica son por tanto es-

${ }^{68}$ Cfr. Alasdair MacIntyre, Whose Justice?, Which Rationality?, Londres 1988, pp. 326 ss. y, sobre éste, Brian Barry, The Light that Failed, en Ethics 100 (1989), pp. 160 s., así como Jürgen Habermas, Erläuterungen zur Diskursethik, Frankfurt a. Main 1991, pp. 209 ss.

${ }^{69}$ Cfr. MacIntyre, Whose Justice? (nota 68), pp. 183 ss., 402 s. En Three Rival Versions of Moral Inquiry. Encyclopedia, Genealogy, and Tradition (Notre Dame 1990, pp. 170 ss., 196 ss.) intenta MacIntyre demostrar la superioridad de la tradición tomista sobre la crítica «enciclopédica» por la Ilustración y la tradición crítica «genealógica» que va desde Nietzsche hasta Foucault. En relación a esta pretensión de quedar como «contextualista» y al mismo tiempo pretender fundamentar la superioridad de la propia tradición, el liberalismo irónico-posmoderno de Rorty no puede sino venir a mostrar nuevamente el «fracaso del pensamiento moral». Cfr. Alasdair MacIntyre, Moral Arguments and Social Contexts. A Response to Rorty, en Robert Hollinger (editor), Hermeneutics and Praxis, Notre Dame 1985 , pp. 222 ss. Rorty había previamente sugerido a MacIntyre que «abandonara también los últimos restos de esta línea \{scil. aristotélica\} de pensamiento». Vid. Richard Rorty, Freud und die moralische Reflexion, en, el mismo, Solidarität oder Objektivität? (nota 60), pp. 38 ss. (63).

${ }^{70}$ Walzer, con su noción de un «universalismo reiterativo», se aproxima a posiciones universalistas todo lo que sus premisas contextualistas se lo permiten. Cfr., el mismo, Zwei Arten des Universalismus, en Babylon, cuaderno 7/1990, p. 7ss. Para una crítica vid. Hauke Brunkhorst, Gesellschaftskritik von innen? Für einen «covering-law»-Universalismus ohne Dogma, en Karl-Otto Apel / Matthias Kettner (editores), Zur Anwendung der Diskursethik in Politik, Recht und Wissenschaft, Frankfurt a. Main 1992, pp. 149 ss.

${ }^{71}$ Michael Walzer, Spheres of Justice, New York 1983. Traducción alemana: Sphären der Gerechtigkeit, Frankfurt a. Main / New York 1992, pp. 61, 440 ss. 
trechos: la filosofía moral, afirma Walzer, se reduce a la mera interpretación de esos estados previamente existentes ${ }^{72}$.

\section{Los dilemas del contextualismo}

Característica común a los postulados de los autores anteriormente citados es la reducción de planteamientos éticos relativos a criterios de regulación justa de conflictos intersubjetivos a cuestiones morales sobre la vida buena, y junto a ello la reducción de los problemas de validez de las normas a los de su vigencia social ${ }^{73}$. Con ello se renuncia al componente crítico inherente a la ética, ya que la representación de lo bueno queda de tal forma limitado que viene a contradecir el sentido mismo de los juicios morales, esto es, que sean susceptibles de una fundamentación universal ${ }^{74}$. La argumentación ética no expresa ningún marco de «intenciones-denosotros», sino que los trasciende. Cuando, por ejemplo, un afectado por la discriminación racial se opone a ciertas normas que aprueban esa discriminación en la sociedad, no puede hacerlo bajo una alegación del tipo «nosotros no hacemos ese tipo de cosas», sino que debe afirmar: «esa norma no puede justificarse», porque los afectados por ella no podrían aceptarla, ya que vulnera principios fundamentales como el de la igual pretensión de respeto o porque quebranta derechos básicos como el de la igualdad.

Por ello, el contextualismo se ve enfrentado al dilema, de que (1) o bien debe negar ya toda posibilidad de crítica al previo ethos local y a las relaciones de poder presentes dentro del mismo, (2) o bien se ve obligado a introducir subrepticiamente contenidos normativos ocultos en su interpretación de un mundo narrativo común.

(1) Alasdair MacIntyre, con su obra After Virtue, aparece como un claro representante de la «propensión positivista» del comunitarismo (Kersting ${ }^{75}$ ), e incluso de la renuncia a toda distancia crítica. La posición de este autor participa de la opinión tradicionalista de otras posturas neoaristotélicas de que las fundamentaciones no son otra cosa que «argumentos y proposiciones guiadas hermenéuticamente al fin de establecer un acercamiento entre los acuerdos individuales y las bases ya asumidas del ethos correspondien-

${ }^{72}$ Vid. Michael Walzer, Interpretation and Social Criticism, Cambridge 1987, pp. 3ss.; traducción alemana: Kritik und Gemeinsinn, Berlin 1990, pp. 9 ss. $(36,42)$

${ }^{73}$ Sobre esta diferenciación cfr. Jürgen Habermas, Vom pragmatischen, ethischen und moralischen Gebrauch der praktischen Vernunft, en, el mismo, Erläuterungen zur Diskursethik (nota 68), pp. 100 ss.

${ }_{74}$ Vid. Ernst Tugendhat, Vorlesungen über Ethik, Frankfurt a. Main 1995, pp. 65 ss.

${ }^{75}$ Wolfgang Kersting, Die Liberalismus-Kommunitarismus-Kontroverse in der amerikanischen politischen Philosophie (nota 46), p. 88. 
te» ${ }^{76}$. Pero el contraste entre la reformulación formal de MacIntyre de la noción de virtud ${ }^{77}$ y su indefinido concepto de la comunidad, y su enérgico rechazo de los derechos del hombre, acentúa virulentamente el problema general de las éticas de la virtud ${ }^{78}$. MacIntyre, a diferencia de Aristóteles, ya no viene a destacar qué disposiciones deben desarrollarse que nos capaciten para ser sencillamente hombres. Por el contrario, establece que a lo que tiende el fomento de las virtudes es a poder desarrollar mejor aquellas prácticas que permiten tender a la unidad narrativa de una vida individual y cuyos bienes inherentes vienen a definir al mismo tiempo los roles funcionales propios de la comunidad tradicional constitutiva del agente ${ }^{79}$. Ahora bien, esas prácticas, según la tradición en que se originen, pueden ser manifiestamente inmorales. Así, el ejemplo de la «práctica» de un comandante nacionalsocialista en un territorio ocupado, la cual, después de un tiempo, acaba por condensarse en el telos y la narrativa de una trayectoria unitaria de vida y por ser concebida como un fin en sí mismo y como una parte funcional primordial de la gran narrativa del cometido histórico de dominación por la raza aria, puede cuanto menos formularse en el lenguaje teórico de MacIntyre ${ }^{80}$. A esta posibilidad, MacIntyre no puede sino oponer la débil esperanza de que no existan esas comunidades, ya que en su concepción metodológica la última instancia decisoria sobre si una práctica es «mala» radica en su funcionalidad o disfuncionalidad para con la propia tradición ${ }^{81}$. En la postura de este autor, queda totalmente cerrado el camino a una crítica superadora de la tradición y verdaderamente ética; al igual, por lo demás, que en la concepción de Rorty, con su esperanza de que una cultura sensible a los fenómenos del dolor y la crueldad pudiera proporcionar la base emocional para que «nuestra liberal», aunque etnocéntrica compren-

${ }^{76}$ Herbert Schnädelbach, Was ist Neoaristotelismus? (nota 5), p. 221. Un caso especial lo constituye la teoría de Martha Nussbaum. Vid. infra nota 100.

${ }^{77}$ Cfr. MacIntyre, Verlust der Tugend (nota 19), pp. 243 ss., 273 ss., y sobre ello y lo siguiente, Ernst Tugendhat, Vorlesungen über Ethik (nota 74), pp. 219 ss.

${ }^{78}$ Cfr. Alan Gewirth, Rights and Virtues, en Review of Metaphysics 38 (1985), pp. 739 ss. (752 ss.). En la argumentación que se realiza a continuación se modifica una objeción a esta contracrítica de Gewirth a MacIntyre; cfr. la obra citada, p. 758: «But which Community? Aristotle's community requires the enslavement of farmers and mechanics; the nazi community required the murder of Jews and others». En cualquier caso, en relación a la conversión de MacIntyre al tomismo en Whose Justice?, Which Rationality?, dicha crítica no puede ser ya acogida sin limitaciones.

${ }^{79}$ Cfr. MacIntyre, Verlust der Tugend (nota 19), pp. 250 ss., 270 s., 274 ss.

${ }^{80}$ MacIntyre podría, ciertamente, objetar que el mismo nacionalsocialismo es una expresión de la modernidad y su «pérdida de la virtud». En ese caso el ejemplo podría modificarse con un inquisidor de brujas del siglo XIV.

${ }^{81}$ Cfr. MacIntyre, Verlust der Tugend (nota 19), pp. 267 ss. También la noción de una «ley moral» (asimismo no universal), como instancia entre la praxis y la tradición (vid. ibidem p.268) permanece para MacIntyre supeditada a esta última. 
sión del grupo, elevara las pretensiones de solidaridad, ampliándola a largo plazo a todos los hombres amenazados por el dolor y la desesperación ${ }^{82}$.

(2) Por el contrario, Sandel y Walzer recurren a introducir subrepticiamente determinados presupuestos normativos. Así, por ejemplo, pretende Sandel mantener que el movimiento americano por los derechos civiles de los años setenta podría justificarse sin recurrir a la noción de los derechos y la dignidad humana, con la afirmación de que consistió en un proceso de reconocimiento de la plena pertenencia de ciertos conciudadanos, quienes hasta ese momento habían sido «incorrectamente» («wrongly») excluidos de la vida comunitaria de la nación ${ }^{83}$. Pero con la distinción correcto/incorrecto, Sandel no tiene más remedio que servirse de un instrumental teórico que previamente había rechazado. Y ello sólo puede hacerlo desde fuera de sus criterios, ya que éstos carecen del aparato conceptual y normativo necesario para poder defender plausiblemente por qué para la gente de raza blanca, por ejemplo en Alabama, las pretensiones de la judicatura constitucional de la «nación» debieran haber sido prioritarias frente a los vínculos constitutivos de la armonia grupal de la mayoritaria cultura racista. Este ejemplo revela, además, otra debilidad estructural de esta concepción, ya que resulta más que plausible sostener que las rejas comunitarias tras las que los individuos de Sandel están encerrados, se conformarán por lo general a partir de pretensiones de lealtad diferentes y contradictorias entre sí. Y el establecimiento expreso de un criterio normativo con el que hubiera de establecerse en cada caso el rango de prioridad de dichas pretensiones de lealtad haría que el edificio teórico de Sandel se derrumbara.

De forma similar, la teoría de las «esferas de la justicia» de Walzer cae en la trampa de un contextualismo que en realidad desearía no serlo. En la obra citada, Walzer realiza el intento de demostrar que la idea de una sociedad justa, democrática y prima facie igualitaria conlleva la exigencia de una distribución de clases diferentes de bienes sociales bajo diferentes reglas. La tensión metodológica, que amenaza con invalidar por completo las tesis de este autor, radica en que por un lado Walzer pretende fundar «un socialismo democrático y descentralizado en el marco de un fuerte estado del bienestar» ${ }^{84}$, y por otro, y dada su predisposición contextualista, debe defenderlo con la apenas sostenible afirmación de que esas instituciones «ya existen en nuestra común forma de comprender los bienes sociales» ${ }^{85}$.To-

${ }^{82}$ Cfr. Rorty, Kontingenz, Ironie und Solidarität (nota 60), pp. 305 ss.

${ }^{83}$ Sandel, Introduction (nota 1), p. 6.

${ }^{84}$ Walzer, Sphären der Gerechtigkeit (nota 71), p. 448.

${ }_{85}$ Walzer, Sphären der Gerechtigkeit (nota 71), p. 19. Que este intento de establecer una teoría normativa con medios descriptivos aboca a ciertas tensiones parece claro cuando Walzer da a entender que una interpretación hermenéutica de la «conciencia colectiva» de la nación americana en los años 80 llevaría, entre otras, a las siguientes convicciones: que una esfera más 
mando el ejemplo de Walzer, Joshua Cohen ha resaltado el «dilema comunitarista básico» ${ }^{86}$ consistente en que, por un lado, las normas de distribución, dado que deben emanar de un proceso hermenéutico interno según las prácticas de distribución existentes en una sociedad, apenas pueden servir para una crítica a lo dado; y, por otro lado, toda consideración crítica o incluso toda fundamentación procedimental de reglas de distribución externas a la tradición vendría a quebrar las bases contextualistas. En cualquiera de los casos, la intención crítica y los métodos contextualistas se opondrían mutuamente ${ }^{87}$. Para lo que aquí pretende destacarse, es importante, de cualquier forma, la salida que según Cohen parece tomar Walzer: este autor, recurriendo a una argumentación basada en la «naturaleza de las cosas», lo que hace es rellenar subrepticiamente sus interpretaciones sobre los «shared understandings» de sus connacionales americanos con determinados contenidos normativos ${ }^{88}:$ «los distribuidores están sujetos a las imposiciones que surgen de los bienes...; podría incluso decirse que los propios bienes se distribuyen entre los sujetos» ${ }^{89}$. Walzer extrae el potencial crítico de su teoría de la circunstancia de que cree poder obtener inductivamente reglas de distribución de los bienes sociales que habrán de ser globales y transhistóricas por el mero hecho de ser razonables ${ }^{90}$. En última instancia, esta argumentación, basada en el «particular fundamento de justicia» ${ }^{91}$ de que los bienes sociales deben tener un valor inherente, viene a ser contraria a las solemnes afirmaciones comunitaristas de Walzer: aunque su contextualismo le obli-

amplia del Estado social, y ello también en relación a la atención médica, sólo debe llevarse a cabo a partir de una medición equitativa de las necesidades (Walzer, Sphären der Gerechtigkeit (nota 71), pp. 134 ss.); que el nivel de renta debe igualarse y democratizarse (pp. 178 ss.); y que las grandes empresas deben establecerse bajo un amplio control de los trabajadores (pp. 426 ss. )

${ }^{86}$ Joshua Cohen, Kommunitarismus und universeller Standpunkt, en Deutsche Zeitschrift für Philosophie 41 (1993), pp. 1009 ss. (1015).

${ }^{87}$ Cfr. sobre ello el tratamiento sistemático de este problema realizado por Miguel Giusti, en Giusti, Topische Paradoxien der kommunitaristischen Argumentation, en Deutsche Zeitschrift für Philosophie 42 (1994), pp. 759 ss. Simon Caney (Liberalism and Communitarianism: a Misconceived Debate, en Political Studies (1992), pp. 273 ss. (288)) señala con razón la ulterior inconsistencia teórica asociada al «simple communitarian dilemma»: La aseveración de Walzer, de que no tomar en consideración una específica forma de vida y sus representaciones sobre la justicia y la moral es «(siempre) una actuación incorrecta» (Sphären der Gerechtigkeit, ( nota 71), pp. 442 ss.) no presupone un concepto no relativo de tolerancia, ya que su punto de partida relativista no podrá fundamentarlo.

${ }^{88}$ La argumentación desarrolla aquí sucintamente una línea de pensamiento ya empleada por Ronald Dworkin en su crítica a la «hidden and mystical premise» de Walzer en su Spheres of Justice. Cfr. Dworkin, What Justice Isn't, en The New York Review of Books, 14.04.1983; reimpreso en, el mismo, A Matter of Principle, Cambridge 1985, pp. 214 ss. (217s.)

${ }^{89}$ Walzer, Sphären der Gerechtigkeit (nota 71); p. 31.

${ }^{90}$ Walzer, Sphären der Gerechtigkeit (nota 71); pp. 35 ss.

${ }^{91}$ Walzer, Sphären der Gerechtigkeit (nota 71); p. 12. 
garía a aceptar como estructura básica dominante de la justicia distributiva local incluso un sistema de castas, siempre que esté suficientemente legitimado por la tradición ${ }^{92}$, exige pese a ello someter a crítica a ese tipo de sistemas con el argumento del significado propio inherente a los bienes sociales y a las esferas de distribución ${ }^{93}$. Los postulados del libro de Walzer vienen a ser, en realidad, un intento de establecer, en lugar de un discurso de fundamentación jurídico y moral, una especie de «pensamiento concreto» $\{$ «konkretes Ordnungsdenken»\} con intenciones democrático-sociales.

La teoría de los bienes sociales de Walzer, que llevan en sí mismos sus propias reglas de distribución, cae, en lo tocante a la fundamentación de normas de justicia distributiva, en el dilema de que, o bien reitera tautológicamente la previa norma implícita en la «naturaleza de las cosas», o bien se sirve de un non sequitur, al concluir un deber ser en lo tocante a su distribución de la mera existencia de un bien ${ }^{94}$. La línea de argumentación «platónica» (Dworkin), y en todo caso monológica, de la «naturaleza de la cosa» conlleva el riesgo de ocupar el puesto que en otro lugar había reservado Walzer a una comprensión democrática del ciudadano no limitada por pretensiones morales de verdad ${ }^{95}$.

A tenor de lo dicho hasta ahora, podría parecer que la relevancia de la discusión sobre el comunitarismo para la filosofía del Derecho es más bien escasa. Sin embargo, si, a pesar de su estructura aporética, se siguiera la tesis contextualista, habría de asumirse lo siguiente. En primer lugar, el contextualismo, dado que pretende eximir a las estructuras normativas internas de las sociedades de un examen basado en un discurso de fundamentación racional, obligaría a abandonar la idea de un «sistema jurídico razonable» \{vernünftigen Rechtssystems\}, en el que los ideales jurídicos, bajo la forma de principios, han de satisfacer la exigencia de un sustrato de razón práctica de naturaleza procedimental ${ }^{96}$. En segundo lugar, desaparecería la idea de una validez universal de los derechos humanos.

${ }_{92}$ Walzer, Sphären der Gerechtigkeit (nota 71); pp. 58 ss., 441 ss.

${ }_{93}$ Walzer, Sphären der Gerechtigkeit ( nota 71), p. 60.

${ }^{94}$ Cfr. también la crítica a Walzer de Wojciech Sadurski, Moral Pluralism and Legal Neutrality, Dordrecht 1990, pp. 61 ss. (66 s.).

${ }_{95}$ Cfr. Michael Walzer, Philosophy and Democracy, en Political Theory 9 (1981), pp. 379 ss. (385 ss.). Esta relación de tensión entre el recurso de Walzer a argumentar desde la «naturaleza de la cosa» y su teoría de la democracia es pasado por alto en el trabajo de Hubertus Buchstein y Rainer Schmalz-Bruns, Gerechtigkeit als Demokratie - zur politischen Philosophie von Michael Walzer, en Politische Vierteljahresschrift 33 (1992), pp. 375 ss.

${ }_{96}$ Cfr. Robert Alexy, Idee und Struktur eines vernünftigen Rechtssystems, en, el mismo/Ralf Dreier / Ulfrid Neumann (editores), Rechts- und Sozialphilosophie in Deutschland heute, ARSP Beiheft 44, Stuttgart 1991, pp. 30 ss.; Jürgen Habermas, Faktizität und Geltung (nota 12), pp. 134 ss., 188 ss., 343 ss., así como Bernhard Peters, Rationalität, Recht und Gesellschaft, Frankfurt a. Main 1991, pp. 272 ss., 314. 


\section{La tesis normativa: Comunidad en vez de justicia}

Siguiendo las consideraciones anteriores, podría generarse la impresión de que el comunitarismo pretende dar una respuesta no política a las cuestiones decididamente políticas de la teoría liberal ${ }^{97}$. Pero esta impresión es falsa, ya que tanto la argumentación ontológica como la metaética de estos autores viene a servir a la finalidad teórico-jurídica de sustituir una «política de los derechos» por una «política del bien común» ${ }^{98}$. El comunitarismo se opone así a la convicción básica liberal de la prioridad de los derechos sobre las concepciones de lo bueno; más concretamente: la convicción de que las libertades básicas del individuo y los principios de la justicia (política) imponen límites irrebasables a toda búsqueda individual y colectiva de la vida «correcta» ${ }^{99}$.

Una «política de lo bueno» puede formularse de diversas formas. Ejemplos de ello, en un ámbito externo a la discusión sobre el comunitarismo, son el esencialismo «aristotélico de izquierdas» de Martha Nussbaum ${ }^{100} \mathrm{y}$ el intento de Joseph Raz de fundar un liberalismo decididamente perfeccionista ${ }^{101}$, los cuales parten de esa política de lo bueno sin por ello asumir un concepto fuerte de comunidad. En todo caso, ambas concepciones precisarían de una discusión propia, que aquí no puede ser abordada. Las siguientes consideraciones se concentrarán en las posturas propiamente «comuni-

${ }^{97}$ Ello mismo es sugerido también por John R. Wallach, Liberals, Communitarians, and the Task of Political Theory, en Political Theory 15 (1987), pp. 581 ss. (591 ss.)

98 Sandel, Liberalism (nota 16), p. 5.

${ }^{99}$ Cfr. por ejemplo John Rawls, Der Vorrang des Rechten und die Idee des Guten, en el mismo, Die Idee des politischen Liberalismus. Aufsätze 1978-1989, Frankfurt a. Main 1982, p. 364 ss.; y del mismo autor, Political Liberalism, (nota 35), pp.174 ss.

${ }^{100}$ Con la noción de una «socialdemocracia aristotélica» lleva a cabo Martha Nussbaum el intento de establecer una concepción esencialista de las funciones y capacidades esenciales del hombre y, con ello, la pretensión de elevar a «la» sociedad el óptimo desarrollo de esas funciones por sus miembros. La «densa y vaga teoría del bien» de Nussbaum es, por un lado, una concepción liberal con tendencias acentuadamente paternalistas y con una noción ambivalente de autonomía individual; pero, por otro, se concibe como una teoría válida transculturalmente, manifestando una explícita separación frente al «relativisimo localista y vinculado a la tradición y al comunitarismo» propio de las tesis contextualistas más arriba citadas Cfr. Martha Nussbaum, Menschliches Tun und soziale Gerechtigkeit. Zur Verteidigung des aristotelischen Essentialismus, en Micha Brumlik / Hauke Brunkhorst (editores), Gemeinschaft und Gerechtigkeit, Frankfurt a. Main 1993, pp. 323 ss. $(334,348)$. Una versión ampliada ha aparecido bajo el título: Human Functioning and Social Justice: In Defense of Aristotelian Essentialism, en Political Theory 20 (1992), pp. 202 ss. Vid. también, de la misma, Aristotelian Social Democracy, en Bruce Douglas et al. (editores), Liberalism and the Good, New York and London 1990, pp. 203 ss., así como, para una visión introductoria, Christiane Scherer, Das menschliche und das gute menschliche Leben. Martha Nussbaum über Essentialismus und menschliche Fähigkeiten, en Deutsche Zeitschrift für Philosophie 41 (1993), pp. 905 ss.

\footnotetext{
101 Joseph Raz, The Morality of Freedom ( nota 54).
} 
taristas», las cuales localizan lo «bueno» en la misma comunitarización \{Vergemeinschaftung \} del individuo y conciben, por tanto, esa comunitarización como un fin en sí mismo. El tema a debatir es, entonces, el relativo al «paradigma de la comunidad» ${ }^{102}$; lo que debemos plantearnos es si resultan fácticamente plausibles y normativamente convincentes los asertos de que la comunitarización, como medio de integración primario en las sociedades complejas, es tanto posible como deseable, y de que, en consecuencia, el Derecho y la moralidad deberían fundirse en una eticidad sustancial.

\section{Conceptos de comunidad}

El «paradigma de la comunidad» se concibe como una teoría de la sociedad que, en última instancia, no se quiere dar por satisfecha con destacar la importancia de los procesos de comunitarización de los individuos en grupos intermediarios y asociaciones pertenecientes a la dimensión de la $\mathrm{ci}$ vil society; sino que además sostiene, como lo hace Sandel, que la misma «estructura institucional básica» de la sociedad ( y no sólo la conducta social de sus ciudadanos) debe conformarse según la comunidad ${ }^{103}$. MacIntyre, por su parte, destaca que la tradición tomista, por él preferida, implica (como cualquier tradición) el (r)establecimiento de un orden social correspondiente ${ }^{104}$. No obstante, en la elaboración del concepto de comunidad como «estructura básica», se muestran los teóricos comunitaristas tan parcos, que sus críticos encuentran razones para hablar de una «comunidad fantasma» ${ }^{105}$. En cualquier caso, se intentará a continuación arrojar un poco de luz sobre el cúmulo de significados que abarca ese concepto.

La imagen dominante es la de una sociedad que se conforma, no sólo sus partes intermediarias sino como un todo ${ }^{106}$, a partir de un modelo de re-

${ }_{102}$ Aquí coinciden el comunitarismo con sectores del Critical Legal Studies Movement. Cfr. sbre ello Richard W. Baumann, The Communitarian Vision of Critical Legal Studies, en Allan C. Hutchinson / Leslie J.M. Green (editores), Law and the Community. The End of Individualism?, Toronto 1989, pp. 9 ss.

${ }^{103}$ Sandel, Liberalism (nota 16), p. 173

${ }^{104}$ Cfr. MacIntyre, Whose Justice?, Which Rationality? (nota 68), p. 391. MacIntyre parece sostener que universidades rivales, incluso vinculadas a tradiciones diferentes podrían representar a medio plazo los núcleos de cristalización de nuevas formas tradicionales de vida; cfr., el mismo, Three Rival Versions of Moral Inquiry (nota 69), pp. 216 ss.

${ }^{105}$ Stephen Holmes, The Permanent Structure of Antiliberal Thought, en Nancy Rosenblum (editora), Liberalism and the Moral Life, Cambridge 1989, pp. 227 ss. Cfr. también Raymond Plant, Community: Concept, Conception, and Ideology, en Politics \& Society 8 (1978), pp. 79 ss.

${ }^{106}$ Cfr. Sandel, Liberalism (nota 16), p. 173: «For a society to be a community in this strong sense, community must be constitutive of the shared self-understandings of the participants and embodied in their institutional arrangements» (cursivas añadidas). En cualquier caso, el nivel de referencia desde el que Sandel mantiene su noción de comunidad queda muy po- 
laciones denominado por Sandel como «situación ideal de la familia». La tesis central sostiene que cuanto más se sustituyan en una comunidad verdadera las relaciones abstractas entre extraños por vinculaciones primarias $\mathrm{y}$ «circumstances of benevolence, or fraternity, or of enlarged affections», menos necesarios serán la justicia y los derechos individuales ${ }^{107}$. De esta forma, la aspiración última sería «to render justice useless, by supplying its place with much noble virtues» ${ }^{108}$. Las comunidades se mantienen cohesionadas a través de un «bien común», de «identidades comunes y fines compartidos» ${ }^{109}$, de «sentimientos fraternos e intereses coincidentes» ${ }^{110}$. En este sentido, se acentúa por estos autores que los vínculos sociales constitutivos no son fruto de una elección, sino que vienen previamente dados ${ }^{111}$. En estas comunidades, la existencia de un vocabulario común y de un «trasfondo de prácticas y acuerdos implícitos» garantiza una adecuada autocomprensión de sus miembros en relación con su sustancia comunitaria ${ }^{112}$. Asimismo, estas comunidades aparecen constituidas por su pasado, son «comunidades de la memoria», que vienen a ofrecer una idealizada interpretación global del mundo, y cuyas pautas de lealtad y compromiso vienen definidos en primer lugar por las costumbres tradicionales de la comunidad ${ }^{113}$. Expresado brevemente, la integración se produce a tavés de los afectos y la tradición.

La noción de comunidad empleada por los comunitaristas, recoge, bajo otros ropajes teóricos, lo que Ferdinard Tönnies había establecido en 1887, en el primer libro de su estudio Gemeinschaft und Gesellschaft. Tönnies definió la Comunidad como un orden de la convivencia que, partiendo de las formas básicas de relación del parentesco, de la vecindad y de la amistad, genera la cohesión social a través de una « mutua actitud de unión común» y de la existencia de determinados «bienes comunes», y en la que

co claro. La capacidad de sustituir la integración a través de la justicia, es decir, por medio del Derecho y de la solidaridad abstracta del Estado social, por «common identities and shared purposes» se la atribuye Sandel tanto a «tribes, neighbourhoods, cities, towns, universities, trade unions, national liberation elements and established nationalisms» como a «ethnic, religious, cultural, and linguistic communities» (p. 31).

${ }^{107}$ Sandel, Liberalism (nota 16), pp. 32 ss.; cfr. p. 83.

${ }_{108}$ Sandel, Liberalism (nota 16), pp. 31 ss. (32), 169, citando a Hume. Para el primer Roberto Unger la comunidad perseguida es nada menos que «the political equivalent of love»; vid. Unger, Knowledge and Politics, New York 1975, p. 261.

109 Sandel, Liberalism (nota 16), pp. 31, 183.

${ }_{110}$ MacIntyre, Whose Justice? Which Rationality? (nota 56), p. 67.

${ }^{111}$ Sandel, Liberalism (nota 16), pp. 150 ss., y MacIntyre, Verlust der Tugend ( nota 19), pp. 294 s.: «Yo me contemplo como (...) portador de una tradición, me guste o no me guste, lo reconozca o no lo reconozca».

${ }_{112}$ Sandel, Liberalism (nota 16), pp. 172 ss. 
la «comprensión» mutua, convertida en habitual, viene a unir a sus miembros por medio de una «armonía» social omniabarcante, conformada a partir de la costumbre y la religión, y se erige en un idealizado «yo más elevado y general». Frente a ésta, la Sociedad era concebida por Tönnies como un agregado de individuos artificialmente surgido a partir de una convención que conforma una «sociedad del intercambio» y la discusión pública, en la que no existe «ningún bien común en realidad» y los individuos «permanecen independientes entre sí y sin vínculos internos mutuos» ${ }^{114}$. A estos dos modelos sociales corresponden, en la concepción de Tönnies, dos formas esenciales de sistema jurídico, el comunitario, en el que los hombres «están unidos entre sí como miembros naturales de un todo», y el de la Sociedad, en el que «como individuos... entran en relaciones entre ellos independientemente» ${ }^{115}$.

Si bien la presentación de Tönnies de las dos «épocas» ${ }^{116}$ de la Comunidad y la Sociedad fue entendida también como la descripción de una historia de la decadencia ${ }^{117}$, y aunque no pueda pasarse por alto la afinidad del autor hacia la primera, con su concepción puso Tönnies de manifiesto que el restablecimiento de una organización de lo social basada en la Comunidad no es ni deseable ni posible ${ }^{118}$. A pesar de todo, el «renacimiento de Tönnies» obtiene su poder de sugestión del trato ambivalente dado a dicho problema, así como de la oscilación entre utopías abstractas y concretas de la comunidad: mientras Sandel sostiene que las condiciones socioestructurales de una sociedad en la que sus procesos de integración todavía adoptan una base jurídica no podrán «ser siempre las dominantes» ${ }^{119}$, presenta el ra-

${ }^{113}$ Robert Bellah et al., Habits of the Heart, Berkeley 1985, en la traducción alemana: Gewohnheiten des Herzens. Individualismus und Gemeinsinn in der amerikanischen Gesellschaft, Köln 1987, pp. 185 ss., 319. Cfr. sobre ello la obra colectiva editada por Charles H. Reynolds / Ralph V. Norman, Community in America. The Challenge of 'Habits of the Heart', Berkeley 1988, y, dentro de ella, en particular el trabajo de Christopher Lasch, The Communitarian Critique of Liberalism, pp. 173 ss.

${ }^{114}$ Ferdinand Tönnies, Gemeinschaft und Gesellschaft. Grundbegriffe der reinen Soziologie [1935 - $8^{\mathrm{a}}$ ed.-], reimpresión, Darmstadt 1991 ( $3^{\mathrm{a}}$ edición), Libro 1, §§ 1, 6, 9, 11, 19, 25; Libro 3, § 4; $\S 1$ ss. ; pp. 1, 12 ss., 17ss., 20, 35, 44, 153 ss., 207 ss.

115 Tönnies, Gemeinschaft und Gesellschaft (nota 114), Libro 3, § 4, ss., p. 154.

116 Tönnies, Gemeinschaft und Gesellschaft ( nota 114), § 7, p. 215.

${ }_{117}$ Cfr. Manfred Riedel, artículo Gemeinschaft, Gesellschaft, en Otto Brunner / Werner Conze / Reinhart Koselleck (editores), Geschichtliche Grundbegriffe, Tomo 2, Stuttgart 1975, pp. 801 ss. (854 ss.).

${ }^{118}$ Cfr. sobre ello Cornelius Bickel, «Gemeinschaft» als kritischer Begriff bei Tönnies, en Carsten Schlüter / Lars Clausen (editores), Renaissance der Gemeinschaft? Stabile Theorie und neue Theoreme, Berlin 1990, p. 17 ss.

119 Sandel, Liberalism (nota 16), p. 183. 
dical antimodernismo ${ }^{120}$ de MacIntyre una línea decididamente utópica, que renuncia a ir dirigido a la realidad de las modernas sociedades (¿dónde establecer si no el tomismo?). Por ello, resulta consecuente que una teoría comunitarista de esa índole haya sido considerada como una continuación de los modelos políticos «comunitaristas-funcionales» de pensadores de la Edad Media como Marsilio de Padua o Juan de Salisbury ${ }^{121}$.

\section{Incorrección descriptiva}

La nueva teoría de sistemas, centrada en las nociones de autopoiesis y de interpenetración, manifiesta un completo rechazo, ya en un nivel conceptual, a tomar en consideración la idea de comunidad (entendida, al modo de Sandel, como una «constitutive conception» ${ }^{122}$ ), definida por aquélla como «una fusión parcial de sistemas sociales y personales» ${ }^{123}$. Aunque no se quisiera manejar esa construcción teórica, ha de compartirse el diagnóstico de que en los sistemas funcionales de las modernas sociedades toda meta-integración a través de la moral queda excluida. Todo sistema funcional depende de que pueda mantener separados su propio código de códigos morales que vendrían a sustituirlo ${ }^{124}$. Especialmente el sistema jurídico, para poder mantener la consistencia de sus decisiones, debe impedir toda vinculación con programas morales y con toda eticidad sustancial ${ }^{125}$. A finales del siglo XX, la flexibilidad y la predecibilidad del Derecho no pueden ser sustituidas por difusas normas morales sustantivas ${ }^{126}$.

Tras la consolidación en las sociedades occidentales de los procesos funcionales estratificados de diferenciación, la inclusión de los individuos

${ }^{120}$ La postura de McIntyre es ciertamente propia de una «sustancialidad por imitación» (Habermas), que, sin ser ya en sí misma tradicionalista, asume un punto de vista interesado en las ventajas de la autoridad de tradiciones no cuestionadas.

${ }^{121}$ Cfr. Cary J. Nederman, Freedom, Community and Function: Communitarian Lessons of Medieval Political Theory, en American Political Science Review 86 (1992), pp. 977 ss.

${ }_{122}$ Sandel, Liberalism (nota 16), pp. 149 ss.: «[One has] to imagine a conception of community that could penetrate the self more profoundly. [...] [For such] members of a society community describes [...] not merely an attribute but a constituent of their identity».

${ }^{123}$ Niklas Luhmann, Soziale Systeme. Grundriß einer allgemeinen Theorie, Frankfurt a. Main 1984, pp. 298 ss.

${ }^{124}$ Cfr. Niklas Luhmann, Gesellschaftsstruktur und Semantik. Studien zur Wissenssoziologie der modernen Gesellschaft, Tomo 3, Frankfurt a. Main 1993, pp. 430 ss.

${ }^{125}$ Cfr. Niklas Luhmann, Das Recht der Gesellschaft, Frankfurt a. Main 1993, pp. 78 ss.

${ }^{126}$ El empleo de la terminología hegeliana nos da un pretexto para manifestar que la recepción de Hegel por el comunitarismo se inspira, ciertamente, en la noción hegeliana de la eticidad $\{$ Sittlichkeit $\}$, pero el significado fuerte que Hegel otorga en la «Filosofía del Derecho» a las nociones de Derecho abstracto, de persona jurídica y de racionalidad de la igualdad general de la ley es sistemáticamente ignorado. Y ello vale también para el Hegel de Taylor (nota 23). Cfr. G.W.F. Hegel, Grundlinien der Philosophie des Rechts, Werke 7, Frankfurt Main 1986, §§ 34 ss., 209 ss., pp. 92 ss., 361 ss. 
en «la sociedad», es decir, la integración social, no puede ya realizarse prioritariamente a través de los sistemas valorativos o morales vigentes ${ }^{127}$. La tesis de Sandel de que la cohesión social depende directamente de las convicciones valorativas sustanciales compartidas por los ciudadanos, incluso en materia de moral sexual ${ }^{128}$, es sociológicamente falsa. Las similares opiniones de algunos textos comunitaristas, que creen ver en la intimidad de las relaciones personales el centro de la sociedad o la forma más completa de los sistemas sociales, deben permanecer irremisiblemente vinculadas a formas pre-modernas de la sociedad ${ }^{129}$. Los «mecanismos de extracción» $\{$ Entbettunsmechanismen $\}$ de la modernidad extrapolan la acción social de relaciones espacialmente limitidas y vienen a deshacer las certezas de la tradición ${ }^{130}$. El cúmulo de diversas formas y estilos de vida propio de las democracias de masas actuales hace «aparecer como una ingenuidad» ${ }^{131}$ la pretensión de una sociedad integrada por una orientación homogénea de valores, y cierra toda posibilidad a la esperanza manifestada, entre otros, por Robert Bellah, de que un consenso comunitario metapolítico de todos los ciudadanos pueda organizarse como una «religión civil» ${ }^{132}$.

La autorreproducción social no depende, por tanto, únicamente del mantenimiento de estructuras simbólicas de formas de vida comunitarias. Junto a la integración social, la sociedad al mismo tiempo se organiza a espaldas de los actores a través de procesos sistémicos diferenciados ${ }^{133}$. Por ello, todo proyecto intencional de socialización debe tener en cuenta esa dimensión no intencional de lo social. Esto significa, por ejemplo, que en la integración de las modernas sociedades debe hacerse frente a problemas de coordinación funcional, los cuales no son asumidos con la mera estabiliza-

${ }^{127}$ Cfr. Luhmann, Gesellschaftsstruktur und Semantik (nota 124), pp. 377 ss., y, el mismo, Soziologische Aufklärung 3, Opladen 1981, pp. 94, 188.

${ }^{128}$ Cfr. Michael Sandel, Moral Argument and Liberal Toleration: Abortion and Homosexuality, en, California Law Review 77 (1989) pp. 521 ss. (536 ss.).

${ }^{129}$ Cfr. Luhmann, Soziale Systeme (nota 123), pp. 303 ss..

${ }^{130}$ Cfr. Anthony Giddens, Konsequenzen der Moderne, Frankfurt Main 1995, pp. 72 ss.

${ }^{131}$ Helmut Dubiel, Zivilreligion in der Massendemokratie, en, el mismo, Ungewißheit und Politik, Frankfurt Main 1994, pp. 151 ss. (151). Vid. también Ulrich Beck / Elisabeth BeckGernsheim, Individualisierung in modernen Gesellschaften - Perspektiven und Kontroversen einer subjektorientierten Soziologie, en, los mismos (editores), Riskante Freiheiten. Individualisierung in modernen Gesellschaften, Frankfurt Main 1994, pp. 10 ss. (34).

${ }_{132}$ Dubiel, Zivilreligion in der Massendemokratie, (nota 131). Vid. Robert Bellah et al., Gewohnheiten des Herzens (nota 113), pp. 255 ss., y, los mismos, The Good Society, New York 1991, pp. 179 ss., así como Stefan Smid, Pluralismus und Zivilreligion, en Der Staat 24 (1985), pp. 3 ss.

${ }^{133}$ Cfr. Jürgen Habermas, Theorie des kommunikativen Handelns, Tomo 2, Frankfurt a. Main 1981, pp. 226 ss. 
ción de identidades colectivas ${ }^{134}$. Este «desacoplamiento entre el sistema y el mundo de vida» (Habermas) escapa completamente a la perspectiva comunitarista; ésta adolece de una cortedad cultural de miras.

\section{La imposición de la armonía}

Pero también en la discusión relativa a la situación cultural de las sociedades actuales ofrece la incorrección descriptiva de las teorías comunitaristas ocasión de preguntarnos por el poder de convicción normativo de ese «paradigma de la comunidad», el cual debe sistemáticamente o bien rechazar ${ }^{135} \mathrm{o}$ bien negar el hecho del pluralismo cultural y el permanente conflicto de las modernas ${ }^{136}$ sociedades. La asunción de un estado constitutivo de la sociedad basado en valores comunes y compartidos, que remite a la posibilidad de «to govern by the common good alone» ${ }^{137}$, ignora dos aspectos: en primer lugar, en las sociedades en las que la diversidad de formas de vida se ha convertido en habitual, las fuentes de las que emana esa supuesta identidad de la comunidad están agotadas, como las tesis sobre el «cambio de valores» vienen a remarcar. A consecuencia de la dinámica social de la individualización ${ }^{138}$, los intentos actuales de orientación social parecen tener lugar más desde criterios internos particulares a cada medio cultural y desde esquemas estéticos cotidianos que desde comunidades constitutivas ${ }^{139}$. El problema al que se enfrenta el comunitarismo es, en expresión de Brian Barry, «akin to that of keepin 'em down on the farm after they've seen Paree, but on a much, much bigger scale» ${ }^{140}$. Expresado de otra forma: si es cierto que la racionalización de imágenes del mundo se presenta como un proceso histórico de aprendizaje, que viene a hacer desaparecer, en tanto superados, los estratos anteriores ${ }^{141}$, entonces todo intento de volver, en

${ }^{134}$ Cfr. Bernhard Peters, Die Integration moderner Gesellschaften, Frankfurt a. Main 1993, pp. 92 ss., 229 ss.

${ }^{135}$ Esto hace abiertamente MacIntyre, Verlust der Tugend (nota 19), p. 210.

${ }^{136}$ Que las referencias históricas de los comunitaristas a la polis aristotélica, a la Edad Media cristiana y a los tiempos fundacionales americanos toman en cuenta estas épocas en forma muy selectiva, ha sido puesto recientemente de manifiesto, una vez más, por Derek L. Phillips (Looking Backward. A Critical Appraisal of Communitarian Thought, Princeton 1993) Sobre el carácter represivo de la «sociedad originaria» bíblico-republicana de los EEUU, vid. también Wolfgang Fach, Der Zeuge Tocqueville, en Christel Zahlmann (editor), Kommunitarismus in der Diskussion, Berlin 1992, pp. 42 ss.

137 Sandel, Liberalism (nota 16), p. 183.

${ }_{138}$ Cfr. Ulrich Beck, Risikogesellschaft, Frankfurt a. Main 1986, pp. 121 ss., y, el mismo/ Elisabeth Beck-Gernsheim, Individualisierung in modernen Gesellschaften (nota 131).

${ }_{139}$ Vid. Gerhard Schulze, Die Erlebnisgesellschaft. Kultursoziologie der Gegenwart, Frankfurt / New York 1993, pp. 67 ss.

${ }_{140}$ Barry, The Light that Failed (nota 68), p. 168.

${ }^{141}$ Cfr. Habermas, Theorie des kommunikativen Handelns (nota 133), Tomo 2, pp. 103 ss. 
las sociedades complejas, a formas de integración basadas en órdenes de valores sustanciales que no sea llevado a cabo a través de medios totalitarios estará condenado al fracaso. En segundo lugar, no puede esperarse que tras las prácticas e instituciones sociales yazca un esquema de valores uniforme, el cual pudiera emplearse como un orden simbólico que sembrara la unidad, ya que dichas prácticas e instituciones no son sino el resultado de numerosos conflictos históricos y sociales ${ }^{142}$. Por ello, querer llegar a una amplia armonía en lo referente a los intereses políticos con nociones como «bien común» «significados sociales compartidos» o «comprensiones básicas comunes» parece no ser más que un «truco de prestidigitador» ${ }^{143}$.

Max Weber, quien reformuló la distinción de Tönnies de Comunidad y Sociedad bajo los términos de comunitarización y socialización, y concibió al primero como la relación social en la que la acción social está basada en «la sensación subjetiva (afectiva o amparada en la tradición) de pertenencia de los miembros», puso de manifiesto que no existe una línea de continuidad (como los actuales comunitaristas gustan de sugerir) entre esta forma de integración y una amplia homogeneidad en los intereses de los miembros Afirmaba, así, Weber, que no deberíamos

«engañarnos sobre el hecho completamente normal de que aun en las comunidades más íntimas haya presiones violentas de toda suerte con respecto a las personas más maleables o transigentes; y tampoco sobre que la "selección" de los tipos y las diferencias en las probabilidades de vida y supervivencia creadas por ella ocurran lo mismo en la comunidad que en otra parte cualquiera» ${ }^{144}$.

En este sentido, contra los nostálgicos de la comunidad podría también ser de aplicación la tesis de Freud relativa a que la formación y estabilización de las masas organizadas (entre las que incluía también las comunidades integradas en torno a valores) debe tener lugar necesariamente a través de la vinculación libidinoso-regresiva con la figura del líder, el cual pasa a ocupar el lugar del yo-ideal de los individuos, al precio de una pérdida de libertad individual ${ }^{145}$.

\section{Consunción del individuo}

El peligro del sometimiento del individuo por la comunidad es la sombra que acecha tras toda forma de comunitarización. Tönnies tenía claro que, a un nivel conceptual, los individuos, asumidos como miembros de la

\footnotetext{
${ }^{142}$ Cfr. Cohen, Kommunitarimus und universeller Standpunkt (nota 86), p. 1015.

${ }_{143}$ Judith N. Shklar, Über Ungerechtigkeit, Berlin 1992, pp. 185 ss (referido expresamente a Walzer).

${ }^{144}$ Max Weber, Soziologische Grundbegriffe, § 9, Tübingen 1976 ( $3^{\text {a }}$ edición), pp. 55 ss.

${ }^{145}$ Vid. Sigmund Freud, Massenpsychologie und Ich-Analyse [1921], Studienausgabe, To-

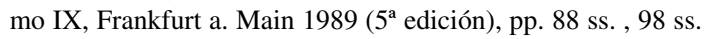


comunidad, sólo podían «aparecer como modificaciones y emanaciones de esa global sustancia orgánica» ${ }^{146}$. La convicción ilustrada, cuestionada in toto por los comunitaristas, de que el interés racional de las personas es el único y último punto de partida imaginable para la creación de las normas, vino a rechazar, por imposibilidad de fundamentación metafísica, la idea de que existen entidades supraindividuales que son en sí mismas valiosas y de las que depende el valor mismo de los individuos ${ }^{147}$. Frente a ello, Sandel sostiene que la noción de «comunidad» no podrá ser asumida hasta que se abandonen las bases teóricas del individualismo ${ }^{148}$. Este autor parece querer entender la comunidad como una especie de meta-persona. A ello tiende cuando sostiene que la comunidad es «a wider subject of possession» ${ }^{149}$; y también cuando, a partir del aserto anterior, afirma que los daños sufridos por los individuos en la persecución de los fines de la comunidad que vienen a constituir su verdadera identidad en realidad no representan para estos individuos un «sacrificio». Dado que el individuo debe su identidad, así como todo su talento y capacidades personales, a los vínculos constitutivos de la comunidad, vive una parte esencial de su vida casi como un agente de esa comunidad: "If I cannot be the owner I can be at least the guardian of the assets located "here", and what is more, a guardian for a communitiy of which I count myself a member» ${ }^{150}$. MacIntyre llega a una conclusión similar, cuando estrecha el ámbito de actuación individual éticamente tolerable a la satisfacción de pautas previas de pertenencia: «Lo que es bueno para mi, debe entonces serlo también para quien ocupa ese mismo rol» ${ }^{151}$.

Característico de toda comunidad es que la persecución por los individuos de la «vida buena» será valorada en función de su contribución a la forma de vida de la propia comunidad y a la consecución de sus bienes comunes. El «valor» social de la persona como «miembro de la comunidad» se mide según el grado en que estén en disposición de realizar esos fines ${ }^{152}$. La categoría que se establece para dicha medición es la del «merecimiento» $\left\{\right.$ Verdienst ${ }^{153}$, que denota un trato y respeto desigual de las personas y que

${ }^{146}$ Tönnies, Gemeinschaft und Gesellschaft (nota 114), Libro 3, § 4, p. 155.

${ }^{147}$ Cfr. Tugendhat, Vorlesungen über Ethik (nota 74), pp. 202 ss.

${ }_{148}$ Sandel, Liberalism (nota 16), p. 151.

149 Sandel, Liberalism (nota 16), p. 144, 149

150 Sandel, Liberalism (nota 16), pp. 143 ss.

151 MacIntyre, Der Verlust der Tugend (nota 19), pp. 294.

${ }^{152}$ Cfr. Axel Honneth, Kampf um Anerkennung. Zur moralischen Grammatik sozialer Konflikte, Frankfurt a. Main 1992, pp. 197 ss.

153 Vid. MacIntyre, Der Verlust der Tugend (nota 19), p. 334. 
llevará, como categoría inversa, al menosprecio de formas de vida y convicciones personales ${ }^{154}$. Puede resultar plausible sostener que el desarrollo personal, en tanto abarque la propia estima, no puede prescindir de esas formas de reconocimiento que sólo pueden tener lugar en comunidades basadas en valores ${ }^{155}$. Lo que resulta ya más problemático de la postura comunitarista es que se pretenda relegar a un lugar secundario -o (como MacIntyre) rechazar completamente- la fundamental dimensión de un Derecho centrado en la dignidad humana y en la noción de los derechos individuales, dirigido (incluso para Hegel ${ }^{156}$ ) a procurar un reconocimiento igual y no jerarquizado de la persona en cuanto tal.

\section{Homogeneización y dominio por la mayoría}

La comunitarización precisa de un elevado grado de homogeneidad en los participantes. Pero en las sociedades complejas esa homogeneidad no surgirá ya espontáneamente, sino que sólo podrá generarse artificialmente a través de procesos simbólicos o reales de exclusión. Y el medio fundamental para esa exclusión física de la comunidad es el sometimiento de las minorías culturales por parte de las mayorías morales. Apenas cabe dudar que, bajo las condiciones de la modernidad, una revitalización de la comunidad como principio de ordenación social habrá de llevar a prácticas de discriminación social ${ }^{157}$. En este sentido, el interrogante que se plantea MacIntyre: «Whose Justice?, Which Rationality?» puede también leerse como: «Whose Values?, Which Majority?».

Un ejemplo de ello, y una de las pocas oportunidades de descender a la política jurídica comunitarista concreta, lo ofrece la discusión de Michael Sandel sobre la legislación penal en materia de homosexualidad ${ }^{158}$. Sandel mantiene incondicionalmente la posición de que el merecimiento de pena de las prácticas homosexuales debe depender directamente de su carácter «moral» $\mathrm{o}$ «inmoral» ${ }^{159}$, y que no deberíamos «andarnos con rodeos» dis-

${ }^{154}$ Cfr. Honneth, Kampf um Anerkennung (nota 152), pp. 217 ss. Cfr. sobre esto, críticamente, Otto Fuchs, Vergemeinschaftung durch den «Kampf um Anerkennung» oder durch Kommunikation, München, 1994.

${ }^{155}$ Cfr. Honneth, Kampf um Anerkennung (nota 152), p. 209, 211. ss., 360 .

${ }^{156}$ Cfr. Hegel, Grundlinien der Philosophie des Rechts (nota 126), §§ 36, 38, 209, pp. 95

${ }^{157}$ Cfr. H.N. Hirsch, The Threnody of Liberalism. Constitutional Liberty and the Renewal of Community, en Political Theory 14 (1986), pp. 423 ss. (435 ss.).

158 Vid. Sandel, Moral Argument and Liberal Toleration (nota 128), pp. 521 ss. La discusión en cuyo marco se situó el artículo de Sandel, aparecida en el California Law Review 77 (1989), pp. 475 ss. tuvo su origen en la Sentencia Bowers v. Hardwick (478 US 186 (1986)). Cfr. también los comentarios sobre Sandel de Moore y Post, ob. cit., pp. 539 ss. y 552 ss., respectivamente.

${ }^{159}$ Vid. Sandel, Moral Argument and Liberal Toleration (nota 128), pp. 521 ss. 
cutiendo si, y en qué grado, la intimidad individual jurídicamente protegida debe ser preservada de la intromisión estatal, más allá de la lesión de intereses ajenos. Ciertamente, con el concepto de lo «moral» no se refiere Sandel a normas universalizables y procedimentalmente fundadas, sino a «bienes» constitutivos de la comunidad ${ }^{160}$. Pero Sandel no puede deducir esos bienes ni de presupuestos esencialistas ni de presupuestos procedimentales, sino que, como ya se dijo, está metodológicamente obligado a extraerlos de la «moral social vigente» en la comunidad, de la que, a su vez, obtienen validez las normas jurídicas. En consecuencia, el proyecto de Sandel implica que el Derecho penal debe proteger con una pena todo contenido «moral» que esté vigente en la mayoría moral y que ésta considere necesario para el mantenimiento de sus formas tradicionles de vida. La ontología de la comunidad propia de estos autores, tras algunos rodeos argumentativos, viene a coincidir enteramente con la posición conservadora que ya hace treinta años criticara contundentemente H.L.A. Hart, en relación a autores como Lord Devlin y Stephen ${ }^{161}$. En ambos casos se llega a la consecuencia sostenida por Sandel, de que las minorías deben modificar su forma de vida hasta que ésta aparezca inofensiva para los valores dominantes; un proceso para el cual la protección jurídica de esferas privadas de libertad no puede ser considerada sino como un obstáculo a superar ${ }^{162}$.

Y es por ello por lo que también ciertos representantes de la black community temen, y no sin motivo, que el retroceso comunitarista de la política a los «shared values» de la clase media blanca dominante excluiría a las minorías del proceso de definición del horizonte valorativo y contribuiría, con ello, a perpetuar la desigualdad entre las razas ${ }^{163}$. Y, aunque la teoría moral y jurídica feminista comparte con las tesis comunitaristas la crítica a la éti-

${ }^{160}$ A partir de esta afirmación, sigue Sandel la estrategia de argumentar que las relaciones homosexuales no habrán de ser punibles siempre que su práctica se acomode a «los importantes bienes humanos» de la mutua lealtad y armonía íntima, que son característicos del matrimonio convencional (p. 534). Sandel, en todo caso, no parece estar dispuesto a establecer un procedimiento por el que pueda determinarse qué bienes deberían ser de aplicación en cada caso.

${ }^{161}$ Cfr. H.L.A. Hart, Law, Liberty, and Morality. The Harry Camp Lectures, Stanford 1963, especialmente pp.. 48 ss., 69 ss.; el mismo, Soziale Bindung und die Durchsetzung der Moral, en , el mismo, Recht und Moral. Drei Aufsätze, editado por Norbert Hoerster, Göttingen 1971, pp. 87 ss.

${ }^{162}$ El intento de Philip Selznick (Dworkin's Unfinished Task, en California Law Review 77 (1989), pp. 505 ss. $(507,513)$ ), de destacar, con Sandel, el Derecho de una comunidad estatal, en la cual, con los medios del Derecho, se impondrá su «orden moral» particular y su «sentido histórico determinado de lo que es una conducta correcta», y, al mismo tiempo, de presentar esa comunidad, a partir del sentido dado por Tönnies, como la intención de una unidad «federal» y no homogénea, que protege sobre todo la integridad de «personas» y «grupos», no puede considerarse sino como contradictorio.

${ }^{163}$ Cfr. Wendy Brown-Scott, The Communitarian State: Lawlessness or Law Reform for African-Americans?, en Harvard Law Review 107 (1994), pp. 1209 ss. 
ca «abstracta» de la justicia y al papel del Derecho como una forma de organización social ${ }^{164}$, hay también autoras feministas que son conscientes de que el movimiento de las mujeres poco podrá esperar de un concepto de comunidad de carácter conservador y basado en la imposición de las mayorías, como el que Sandel y MacIntyre, entre otros, defienden ${ }^{165}$.

\section{Derecho y moral}

Si bien a lo que aspiran los comunitaristas es al establecimiento de una sociedad cohesionada en torno a valores en vez de a través del Derecho, en lo relativo al concreto ámbito de la política jurídica sus posturas parecen apuntar al más modesto proyecto de asimilación, al menos parcial, de la moral y el Derecho, el cual puede ser correctamente descrito como la «colonización del Derecho por el mundo de la vida». A partir del mismo, el control social dejaría de ser realizado a través de un Derecho diferenciado de otros sistemas normativos, siendo sustituido por una serie de normas sociales, espontáneamente generadas y que, por tanto, no habrían de ser sometidas a un control procedimental. Y a medio plazo, el proyecto del comunitarismo «integracionista» parece poner más esperanzas en la salutífera presión social de los defensores locales de la moral comunitaria ${ }^{166}$ que en el Derecho. Junto a ello surge la sospecha generalizada, perteneciente al bien común comunitarista, de que la apelación a los derechos será potencialmente lesiva de la comunidad ${ }^{167}$, la cual traerá consigo un deseado efecto de agravación de los problemas de acceso a la ley, ya que serían cada vez menos de entre los afectados, que podrían recurrir a los derechos individuales como un medio de alejamiento del horizonte valorativo común, los que estarían en disposición de alejarse psicológicamente de ese rol social ${ }^{168}$. El Derecho debe, desde esta perspectiva, venir sobre todo a expresar los valores sustantivos de la co-

${ }^{164}$ Vid., para una perspectiva general, Virginia Held (editora), Justice and Care: Essential Readings in Feminist Ethics, Boulder 1995; la misma, Feminist Morality and Rights, en Rivista Europea di Diritto, Filosofia e Informatica 1995/2 (17th IVR World Congress Bologna 1995, Plenary and Parallel Sessions) pp. 153 ss.

${ }^{165}$ Cfr. Marilyn Friedman, Feminism and Modern Friendship: Dislocating the Community, en Ethics 99 (1989), pp. 275 ss.; y Donna Greschner, Feminist Concerns with the New Communitarians: We Don't Need Another Hero, en Allan C. Hutchinson / Leslie M. Green (editores), Law and the Community. The End of Individualism?, Toronto 1989, pp. 119 ss.

${ }^{166}$ Cfr. Etzioni, The Spirit of Community (nota 2), pp. 34 ss.

${ }^{167}$ Etzioni, The Spirit of Community (nota 2); Charles Taylor, Atomism (nota 50).

${ }_{168}$ Joel Handler (Law and the Search for Community, Philadelphia 1990, p. 9, 85 ss.) forma parte, por el contrario, de los pocos autores que aspiran a una noción de comunidad entendida desde un punto de vista dialógico, con el que pretenden romper las relaciones clientelares jerárquicas entre la burocracia y los destinatarios del Estado del bienestar y crear con ello ámbitos de actuación individual, en vez de reducirlos. 
munidad, de modo que la legislación simbólica adquirirá un mayor protagonismo ${ }^{169}$. Los conceptos jurídicos que habrán de obtenerse de los valores de la moral local (en lugar de a través de concepciones más controlables racionalmente, como por ejemplo la de una eficacia horizontal \{Drittwirkung\} mediata de los derechos fundamentales) serán vagos e indeterminados. Y estos elementos propios de las comunidades sustanciales, antes de que pudieran articularse por la legislación, se filtrarían en el Derecho a través de las decisiones judiciales. Con ello el comunitarismo aspira a una organización de lo político lo más limitada posible, basada en formas rígidas de autoadministración local; y se llega a una desvalorización del ámbito común de lo político, el cual, y frente a las oscilaciones arbitrarias de las preferencias locales, sólo una «lógica universalizadora del Derecho» ${ }^{170}$, puede garantizar, y que resulta imprescindible también para la protección de los individuos.

\section{Comunidad y democracia}

Pocas veces omiten los textos comunitaristas mencionar, junto a la crítica a la supremacía del status negativus en la política liberal, una exigencia dirigida a dar mayor valor al status activus del ciudadano, siendo éste normalmente concebido por la tradición republicana como el ámbito fundamental para el desarrollo de la virtud. Pero lo cierto es que el modelo «integracionista» de comunidad y el autogobierno democrático concurren en una relación de tensión, como, de nuevo, puede contemplarse en la posición de Michael Sandel. Su intento de mostrar que la comunidad sustancial y la política participativa se implican mutuamente no resulta convincente. Resulta ciertamente difícil de entender cómo puede ser democrática una comunidad en la cual los ciudadanos renuncian en tan alto grado a su autonomía, como es la planteada por Sandel ${ }^{171}$. Para este autor, también una nación democrática, entendida como comunidad, sólo podrá serlo realmente en tanto ya esté asumida introspectivamente como sustancia por los individuos, y no cuando surja en forma cooperativa a través de un proceso democrático. Entonces, cuanto más intenso sea el consenso sobre la comunidad, a partir del grado de identificación de los individuos y sus intereses con un colectivo simbólico y sus intereses, menos necesaria -y más perjudicial- habrá de ser la deliberación ${ }^{172}$. Ciertamente, lo que Sandel debería determinar es si

\footnotetext{
169 Amitai Etzioni, The Spirit of Community (nota 2), p. 81.

${ }^{170}$ Sandel, Die verfahrensrechtliche Republik und das ungebundene Selbst (nota 16), pp. 33 ss., y, el mismo, Introduction (nota 1), p. 6.

171 Sobre la relación entre un individualismo asegurador de bienes y una individualidad democrática, vid. George Kateb, Democratic Individuality and the Meaning of Rights, en Nancy Rosenblum (editora), Liberalism and the Moral Life, Cambridge 1989, pp. 183 ss.

${ }^{172}$ Cfr. Barber, Starke Demokratie (nota 10), pp. 142 ss.
} 
existe en realidad alguna diferencia entre su noción de «participación», la que vincula a una previa homogeneización de los participantes ${ }^{173}$, y la idea de una «acclamatio» ${ }^{174}$ de los miembros, dirigida al robustecimento de esa sustancia supraindividual.

Y tampoco resulta convincente la afirmación de Sandel de que el comunitarismo fomenta el desarrollo de competencias deliberativas entre los buenos ciudadanos ${ }^{175}$, ya que con su posición no puede explicar por qué deberían tener un carácter más marcadamente constitutivo los vínculos de los individuos al Estado democrático y su trato para con éstos como citoyens que las pretensiones de integridad de sus comunidades intermedias. Sandel, a diferencia de Aristóteles, ni siquiera intenta fundamentar por qué el Estado es «la más relevante de todas las comunidades» ${ }^{176}$. MacIntyre, en cambio, resulta en este aspecto más consecuente, al afirmar que las comunidades cohesionadas por la tradición que él defiende ponen en juego su identidad ya con la mera participación en la «discusión pública» y que, por ello, el orden político moderno, incapaz de establecer una comunidad moral sustancial, «desde un punto de vista que debe verdadera fidelidad a la tradicion de las virtudes» ${ }^{177}$ debe ser sencillamente rechazado.

\section{Compatibilidad entre comunidades}

A ello aparece unido el problema ulterior de que si partimos de los presupuestos contextualistas de Sandel, MacIntyre, Walzer o Rorty, resulta inviable establecer un marco de intermediación entre las diferentes comunidades sustanciales basado en normas independientes del contexto. ¿Cómo puede entonces llegarse a un entendimiento ético entre culturas cuyo único sostén moral es la particular tradición de cada una? Sólo quedaría (en el mejor de los casos) una relación basada en el intercambio de intereses y en la tolerancia; pero también un abierto dominio de una sobre otra, ya que en conflictos de valores, que inevitablemente habrán de surgir entre comprensiones del mundo cuasi-autistas, las condiciones que propiciarían una renuncia al en-

${ }^{173}$ Sandel, Liberalism (nota 16), p. 151: «And while "association" and "co-operation" typically presuppose the antecedent plurality of those who join together to associate or co-operate, "community" and "participation" may describe a form of life in which the members find themselves commonly situated "to begin with", their commonality consisting less in relationships they have entered than in attachments they have found».

${ }^{174}$ Cfr. el intento (decididamente autocrático) «rousseaunista» de Carl Schmitt de decir adiós al liberalismo y de mantener una «democracia» homogénea; en, el mismo, Zur Geistesgeschichtlichen Lage des heutigen Parlamentarismus, Berlin [1923],1961 (3ª edición), especialmente pp. 20 ss.

${ }^{175}$ Cfr. Sandel, Introduction (nota 1), p. 6.

176 Aristoteles, Politik, 1252a ff.

177 MacIntyre, Der Verlust der Tugend (nota 19), pp. 335 ss., 339. 
frentamiento suelen ser mínimas, por el hecho de que esos conflictos sólo podrán ser asumidos por las partes contendientes como juegos de suma cero ${ }^{178}$ : los intereses pueden ser discutidos, las normas pueden fundamentarse discursivamente; pero las comprensiones del mundo se excluyen mutuamente. La distinción amigo/enemigo no es el concepto de lo político, pero sí es el criterio político propio de las comunidades y sus relaciones entre sí. En una época de creciente globalización de las relaciones e interdependencias sociales, la alternativa del comunitarismo no parece abrir expectativas pacíficas ${ }^{179}$.

\section{La inevitabilidad del Derecho}

Lo expresado hasta ahora puede resumirse en la tesis de que la concepción comunitarista de la comunidad, si no quiere convertirse en totalitaria, está enfrentada al dilema de que, a la vez que no puede prescindir del funcionamiento de las estructuras jurídicas, se opone a ellas y tiende a su erosión.

(1) Sólo un Derecho que sea neutral respecto a las concepciones individuales sobre la «vida buena» puede establecer aquellas «condiciones necesarias para posibilitar, desde el trasfondo de la modernidad, una situación adecuada de realización de las pretensiones de los comunitaristas sobre la importancia de la pertenencia social y de un proyecto personal de integración valorativa» ${ }^{180}$. Es la noción de la persona de derecho \{Rechtsperson $\}$, tan denostada por los comunitaristas, la que ha de servir como «envoltura

${ }^{178}$ Cfr. todavía Vilhelm Aubert, Competition and Dissensus, en Journal of Conflict Resolution 7 (1963), pp. 26 ss.; con ello, vid. Rhoda E. Howard, Human Rights and the Search for Community, en Journal of Peace Research 32 (1995), pp. 1 ss., mencionando la relación existente entre las «comunidades exclusivistas» y la «violencia doméstica e internacional».

${ }^{179}$ El empleo por Michael Walzer en «Sphären der Gerechtigkeit» (nota 71) de las «convicciones compartidas» para determinar las normas de distribución y organización dentro de una comunidad política requiere un alto grado de homogeneidad cultural. En Estados en los que esto no se da, ello llevará a particiones y disminuciones cada vez más intensas de las unidades, lo que a su vez llevará a menudo a que ciertas minorías serán culturalmente primadas. Así, afirma correctamente Kymlicka (Walzer and Minority Rights, en, el mismo, Liberalism, Community, and Culture (nota 35), pp. 220 ss. (228)): «[M]inorities must either play by the rules of the majority culture, without any special protection, or get out entirely and play their own game. This is [...] a multiply perverse view». Con ello, Walzer se retrotrae a un momento anterior al del Derecho natural, el cual, frente a la disolución de la comunidad cristiana en facciones rivales, reaccionó con el intento de fundar una serie de normas comunes a partir del marco omniabarcador de la racionalidad humana. En última instancia, su trabajo de 1983 persigue nada menos que una revisión de la pacificación de los conflictos religiosos y étnicos a través de su integración histórica en órdenes políticos-jurídicos a través de un proceso de nation-building. En todo caso, Walzer ha modificado posteriomente esta posición. Cfr., el mismo, Zivile Gesellschaft und amerikanische Demokratie, Berlin 1992, pp. 100 ss., 115 ss., 140 ss.

${ }^{180}$ Wolfgang Kersting, Die Liberalismus-Kommunitarismus-Kontroverse in der amerikanischen politischen Philosophie (nota 46), p. 98. Vid. también Allen E. Buchanan, Assessing the Communitarian Critique of Liberalism, en Ethics 99 (1989), pp. 852 ss. (858ss., 867 ss.). 
de protección» de las identidades morales ${ }^{181}$, por el hecho de que, a través de la garantía jurídica de la libertad personal, abre a todo individuo la posibilidad de buscar su comunidad conjuntamente con los demás, sin tener que temer por comunitarizaciones forzosas rivales. Un Estado concebido en sí mismo como una comunidad fuerte, y en el que unos supuestos valores mayoritarios se impusieran por medio de la coerción jurídica, vendría a amenazar las estructuras de toda comunitarización intermedia y subcultural dentro de la «civil society». El cometido genuino del Derecho, en este sentido, es tanto garantizar las formas básicas de reconocimiento de las personas en cuanto personas que protegen a los individuos de caer en la nada a través de las redes de las comunidades, como establecer las estructuras que permitan a esos individuos abandonar sus comunidades y entrar a formar parte de otras nuevas ${ }^{182}$.

La construcción teórica de Walzer (véase supra), pero también la de Taylor y la del mismo MacInyre, precisan del necesario complemento de un sistema de derechos situado en un nivel superior a las propias comunidades. En su más reciente trabajo, Charles Taylor intenta desarrollar un proyecto de reconstrucción hermenéutica de la identidad propia de la modernidad, para lo que, desde la concepción de la política y la cultura de los países occidentales, establece tres ideas rectoras: la idea de profundidad interior y de autorreflexividad, una afirmación de la «vida cotidiana», y una imagen expresiva $\{$ expressivistische $\}$ de la naturaleza humana. Estas ideas vienen a suponer unos «hiperbienes» que Taylor califica como «fuentes morales» permamentes. Con ello, se asume implícitamente la tesis de que toda ética es en última instancia una «ética de bienes» ${ }^{183}$, y que, por tanto, la teoría ética y jurídica deontológica es sencillamente una más de las muchas versiones sustanciales de lo bueno, concretamente la que da prioridad a un respeto mutuo y universal y a la autonomía individual ${ }^{184}$. La teoría de Taylor pretende resaltar que una identidad vivida «completa» condiciona el siempre precario intento de una síntesis individual de esos bienes ${ }^{185}$. No obstante, en el momento en que Taylor retorna de las alturas de la historia de la cultura

${ }^{181}$ Cfr. Rainer Forst, Kontexte der Gerechtigkeit. Politische Philosophie jenseits von Liberalismus und Kommunitarismus, Frankfurt a. Main 1994, pp. 113 ss.

${ }_{182}$ Vid. Jeremy Waldron, When Justice Replaces Affection: The Need for Rights, en, el mismo, Liberal Rights. Collected Papers 1981-1991, Cambridge 1993, pp. 370 ss.

${ }^{183}$ Cfr., para una crítica, Forst, Kontexte der Gerechtigkeit (nota 181), pp. 326 ss. y Habermas, Erläuterungen zur Diskursethik (nota 68), pp. 176 ss.

${ }^{184}$ Cfr. Taylor, Sources of the Self (nota 25), pp. 53 ss., 88, y, el mismo, Die Motive einer Verfahrensethik, en Wolfgang Kuhlmann (editor), Moralität und Sittlichkeit. Das Problem Hegels und die Diskursethik, Frankfurt a. Main 1986, pp. 101 ss. (131 ss.)

${ }^{185}$ Cfr. Taylor, Sources of the Self (nota 25), p. 504, y, el mismo, Das Unbehagen an der Moderne, Frankfurt a. Main 1995. 
a la tierra del orden político se ve obligado a reconocer ${ }^{186}$ que para delimitar el ámbito de su propia búsqueda individual sus modernos sujetos orientados en torno a los bienes, no pueden sino recurrir a una noción de Derecho, entendido «como esencia de las condiciones que permiten reunir el arbitrio de uno con el arbitrio del otro en una ley general de la libertad» ${ }^{187}$. Así, la concepción de Taylor acaba por verse obligada a otorgar a un Derecho éticamente neutral, el cual había sido considerado meramente como una concepción más de lo bueno, un papel omnímodo, apareciendo como una condición cuasitrascendental de la misma búsqueda de los bienes $-\mathrm{O}$, expresado en la terminología de Taylor: el papel de un «meta-hiperbien»-. Algo similar puede afirmarse de MacIntyre, quien, en su más reciente aportación teórica ${ }^{188}$, considera la idea de los derechos como una más -la liberalde las «tradiciones» opuestas e incompatibles entre sí. Pero para MacIntyre, estas tradiciones institucionalizadas, aisladas unas de otras, han de concurrir, en pacífica oposición, en una misma sociedad, aspirando a la hegemonía cultural, lo que, a su vez, parece impensable sin la existencia de unas reglas de juego superiores y externas a cada tradición, las cuales sólo podrán adoptar una articulación jurídica.

(2) En cualquier caso, a la pretensión del comunitarismo «integracionista» de sustituir una «política de los derechos» por una «política del bien común» subyace la falacia consistente en que, del hecho de que otorgar una atención prioritaria a los derechos individuales no haya de ser razón suficiente para afirmar la «bondad» de una sociedad, terminan por concluir que esa atención primordial a los derechos ni siquiera es razón necesaria para afirmar dicha bondad. Con ello, estos autores vienen a socabar los requisitos motivacionales del acatamiento de las leyes: por un lado, pretenden que los individuos, como miembros de comunidades constitutivas integradas en torno a valores morales, defiendan sus lealtades locales y particulares frente a los preceptos aparentemente abstractos emanados de una ética deontológica y frente al principio de igualdad ante la ley ${ }^{189}$. Por otro lado, en el marco de esa reorganización comunitarista de la sociedad, a medio plazo

\footnotetext{
${ }^{186}$ Parece hacerlo cuando reconoce que es posible «to be strongly in favour of a morality based on a notion of the good but to lean to some procedural formula when it comes to the principles of politics» (Sources of the Self (nota 25), pp. 532, nota 60, cursivas añadidas). Más clara, en relación a la imposibilidad de renunciar a los derechos fundamentales, es la posición de Taylor en Multikulturalismus und die Politik der Anerkennung, Frankfurt a. Main 1993, p. 53.

${ }^{187}$ Immanuel Kant, Metaphysik der Sitten, Werkausgabe VIII, Frankfurt a. Main 1977, p. 337.

${ }^{188}$ Cfr. MacIntyre, Three Rival Versions of Moral Inquiry (nota 69), pp. 216 ss.

${ }^{189}$ Cfr. sobre ello la más moderada posición de Philip Selznicks, The Moral Commonwealth. Social Theory and the Promise of Community, Berkeley 1992, pp. 193 ss. y, el mismo, Dworkin's Unfinished Task (nota 162), pp. 505 ss. (513).
} 
habrá de exigirse a las minorías que adopten la identidad que las mayorías hayan dispuesto para ellas, y ello, en caso necesario, habrá de ser realizado con los medios propios del Derecho. El efecto deslegitimador que esa estrategia conllevaría para el sistema jurídico es evidente ${ }^{190}$.

Asimismo, los mecanismos de cohesión social que, tras la desaparición de una comprensión integradora del mundo, habrían de subvenir a la integración de la sociedad, resultarán más perjudiciales que beneficiosos. Frente a la aseveración de Sandel, relativa a las posiciones de Rawls y Dworkin, de que el Estado liberal no es capaz de asumir los deberes de redistribución propios del Estado social ${ }^{191}$, sería, por el contrario, el comunitarismo el que destruiría los presupuestos motivacionales de la solidaridad abstracta, ya que ese «encumbered self» totalmente integrado en la comunidad local no podría desarrollar ninguna noción de justicia posconvencional en relación a las «necesidades de los extraños» (Ignatieff) ${ }^{192}$.

Por otra parte, desde el punto de vista de una sociología de roles, la comunitarización sustancial deja inermes a los individuos inmersos en la misma, ya que impide el desarrollo de los requisitos cognitivos necesarios para la acción racional individual y colectiva, que sólo pueden surgir dentro del entramado de relaciones complejas y múltiple articulación de roles propio de las sociedades modernas ${ }^{193}$; hecho este que encuentra reminiscencias ya en la maliciosa tesis de Nietzsche relativa a la vinculación directa entre las comunidades tradicionales y el embrutecimiento ${ }^{194}$.

${ }^{190}$ Cfr. Kymlicka, Contemporary Political Philosophy (nota 38), p. 228

${ }^{191}$ Cfr. Sandel, Liberalism (nota 16), p. 66.

${ }_{192}$ Michael Ignatieff, The Needs of Strangers, London 1984. Alan Wolfe (Whose Keeper? Social Science and Moral Obligation, Berkeley 1989) acentúa, por el contrario, el papel de los grupos intermediarios en la sociedad civil para el aprendijzaje de las reglas y formas de conducta morales que fundamentan úncamente obligaciones locales en «small-scale worlds». Wolf cree, sin embargo, en la posibilidad de que los recursos motivacionales de la solidaridad abstracta, en sociedades que trasciendan el contexto local, se generen a partir de las fuentes de la moral inherente a las relaciones íntimas, sin recurrir al mito de la existencia de comunidades fuertes.

${ }^{193}$ «[U]nder social conditions offering predominantly simple role sets, the lack of a basic source of disturbance is also a lack of a basic source for reflection. [...] A gemeinschaft may prevent individuals from articulating their roles in relation to the complexities of the outside world» (Rose Laub Coser, In Defense of Modernity. Role Complexity and Individual Autonomy, Stanford 1991, pp. 25 ss., pp. 71 ss., 167 ss.).

${ }^{194}$ Friedrich Nietzsche, Menschliches, Allzumenschliches I (1878), Párrafo 244, Kritische Studienausgabe, Tomo 2, Munich, 1988: «La historia nos enseña que la raza de un pueblo que se conserva mejor es aquélla en que la mayoría de los individuos tienen un vivo sentimiento común, causa de la identidad de sus principios esenciales, habituales e indiscutibles, consecuentemente, por tanto, con su creencia común (...) El peligro de estas comunidades, fundadas en individuos característicos de una misma índole, es el embrutecimiento paulatino acrecentado por herencia, el cual sigue, por lo demás, a la estabilidad como si fuese su sombra». 
Por último, la insistente afirmación comunitarista de que los vínculos de la comunidad deben ser previos y no pueden ser elegidos ${ }^{195}$ se sitúa en directa oposición a toda forma de relación comunitaria compatible con una sociedad compleja, con el pluralismo y la diferencia, marco donde residen las verdaderas fuentes de la solidaridad en las modernas sociedades.

En conclusión, tras un análisis más detallado, las genéricas afirmaciones sobre la atomización, la anomia y la pérdida de pautas morales de las modernas sociedades ${ }^{196}$ aparecen necesitadas de revisión. La solidaridad es un producto de la modernidad que sólo puede surgir en la medida en que los lazos coercitivos de las comunidades tradicionales se debiliten: «que éstos se rompan, no implica la disolución de los vínculos sociales, sino su transformación. El compromiso social que se exterioriza en la solidaridad no se reducirá con la tendencia a la individualización; sencillamente ganará en espontaneidad, en honestidad, en diversidad» ${ }^{197}$. Tras la erosión de las pautas tradicionales de interrelación, pasan a ocupar el primer plano las formas de socialización que dejan a elección del individuo la decisión sobre su participación. Por ello, sólo un marco de relaciones sociales espontáneamente creado y con una estructura abierta puede cumplir lo que el comunitarismo promete. Y para ello son requisitos esenciales tanto la protección jurídica de la libertad individual, como un grado suficiente de «capacidad de elección» ${ }^{198}$ y de competencias sociales postradicionales para la creación de dichas relaciones sociales; precisamente aquellos presupuestos que ha pretendido rechazar el comunitarismo integracionista.

Si el problema radica en el Estado liberal, ¿cómo podría ser el comunitarismo la solución?

(Trad. de Rafael Alcácer Guirao)

${ }^{195}$ Cfr. sobre todo Sandel, Liberalism (nota 1), pp. 149 ss.; MacIntyre, Verlust der Tugend (nota 19), pp. 293 ss.

196 Vid. por ejemplo Bellah et al, The Good Society, (nota 132), pp. 266 ss.

${ }^{197}$ Karl-Otto Hondrich / Claudia Koch-Arzberger, Solidarität in der modernen Gesellschaft, Frankfurt a. Main 1992, pp. 20s., 114 ss.

${ }^{198}$ Heiner Keupp, Ambivalenzen postmoderner Identität, en Ulrich Beck / Elisabeth BeckGernsheim (editores), Riskante Freiheiten. Individualisierung in modernen Gesellschaften, (nota 131), pp. 336 ss. (343).

\section{DOXA 22 (1999)}

